\title{
Partial Loss of Presenilin Impairs Age-Dependent Neuronal Survival in the Cerebral Cortex
}

\author{
Hirotaka Watanabe, ${ }^{1}$ Minah Iqbal, ${ }^{1}$ Jin Zheng, ${ }^{1}$ Mary Wines-Samuelson, ${ }^{1}$ and Jie Shen ${ }^{1,2}$ \\ ${ }^{1}$ Center for Neurologic Diseases, Department of Neurology, Brigham \& Women's Hospital, Boston, Massachusetts 02115, and ${ }^{2}$ Program in Neuroscience, \\ Harvard Medical School, Boston, Massachusetts 02115
}

Mutations in the presenilin (PSEN1 and PSEN2) genes are linked to familial Alzheimer's disease (AD) and cause loss of its essential function. Complete inactivation of presenilins in excitatory neurons of the adult mouse cerebral cortex results in progressive memory impairment and age-dependent neurodegeneration, recapitulating key features of AD. In this study, we examine the effects of varying presenilin dosage on cortical neuron survival by generating presenilin-1 conditional knock-out (PS1 cK0) mice carrying two, one, or zero copies of the PS 2 gene. We found that $P S 1 \mathrm{cKO} ; P S 2^{+/-}$mice at 16 months exhibit marked neurodegeneration in the cerebral cortex with $\sim 17 \%$ reduction of cortical volume and neuron number, as well as astrogliosis and microgliosis compared with $\sim 50 \%$ reduction of cortical volume and neuron number in PS1 cKO;PS2 $2^{-1-}$ mice. Moreover, there are more apoptotic neurons labeled by activated caspase-3 immunoreactivity and TUNEL assay in PS1 cKO;PS2 ${ }^{+/-}$mice at 16 months, whereas apoptotic neurons are increased in the PS1 cK0; $P S 2^{-1-}$ cerebral cortex at 4 months. The accumulation of the C-terminal fragments of the amyloid precursor protein is inversely correlated with PS dosage. Interestingly, levels of PS2 are higher in the cerebral cortex of PS1 cK0 mice, suggesting a compensatory upregulation that may provide protection against neurodegeneration in these mice. Together, our findings show that partial to complete loss of presenilin activity causes progressively more severe neurodegeneration in the mouse cerebral cortex during aging, suggesting that impaired presenilin function by PSEN mutations may lead to neurodegeneration and dementia in AD.

Key words: Alzheimers disease; conditional knockout; dementia; gamma-secretase; neurodegeneration; neuronal survival

\section{Introduction}

Alzheimer's disease $(\mathrm{AD})$ is the most common neurodegenerative disorder, and mutations in the presenilin (PSEN) genes account for $\sim 90 \%$ of the identified familial AD (FAD) mutations. Presenilins are expressed broadly throughout life and serve as the integral catalytic subunit of the $\gamma$-secretase complex (Li et al., 2000). PS1 and PS2 have overlapping functions and are required for development and adult brain functions (Wines-Samuelson and Shen, 2005; Ho and Shen, 2011). The presenilin-1 (PS1) knock-out $(\mathrm{KO})$ mice show perinatal lethality and impaired neural development (Shen et al., 1997; Handler et al., 2000; WinesSamuelson et al., 2005), whereas PS2 KO mice have little detectable phenotypes (Steiner et al., 1999), but PS1/2 double KO mice exhibit more severe phenotypes and die at embryonic day 9 (Donoviel et al., 1999).

To circumvent the perinatal lethality of PS1 KO mice, we previously generated conditional $\mathrm{KO}$ (cKO) mice lacking PS1 in

\footnotetext{
Received Aug. 6, 2014; revised 0ct. 2, 2014; accepted 0ct. 9, 2014

Author contributions: H.W. and J.S. designed research; H.W., M.I., J.Z., and M.W.-S. performed research; H.W. analyzed data; H.W. and J.S. wrote the paper.

This work was supported by National Institutes of Health Grants R01NS041783 and R01NS042818 (J.S.). We thank H. Zhao for breeding and genotyping the mice and other laboratory members for helpful discussions.

The authors declare no competing financial interests.

Correspondence should be addressed to Dr. Jie Shen, Center for Neurologic Diseases, Brigham and Women's Hospital, Program in Neuroscience, Harvard Medical School, 77 Avenue Louis Pasteur, New Research Building 636E, Boston, MA 02115. E-mail: jshen@rics.bwh.harvard.edu.

DOI:10.1523/JNEUROSCI.3261-14.2014

Copyright $\odot 2014$ the authors $\quad 0270-6474 / 14 / 3415912-11 \$ 15.00 / 0$
}

excitatory neurons of the adult cerebral cortex and found memory impairment in these mice (Yu et al., 2001). Furthermore, loss of both presenilins in conditional double $\mathrm{KO}(\mathrm{cDKO})$ mice results in striking age-dependent neurodegeneration, as well as synaptic and memory impairment (Beglopoulos et al., 2004; Feng et al., 2004; Saura et al., 2004; Zhang et al., 2009, 2010; WinesSamuelson et al., 2010; Wu et al., 2013). Interestingly, presenilins promote memory and neuronal survival and maintain synaptic function in a $\gamma$-secretase-dependent manner, because conditional inactivation of another component of the $\gamma$-secretase complex, nicastrin, results in similar memory impairment, synaptic dysfunction, and age-related neurodegeneration (Tabuchi et al., 2009; Lee et al., 2014). Thus, complete loss of PS/ $\gamma$-secretase function in the adult mouse cerebral cortex recapitulates key features of $\mathrm{AD}$, including age-dependent neurodegeneration, progressive memory impairment, tau hyperphosphorylation, and gliosis.

PSEN mutations confer partial loss of its presenilin function, and some mutations result in complete loss of its activity (Levitan et al., 1996; Song et al., 1999; Moehlmann et al., 2002; Seidner et al., 2006; Heilig et al., 2010). These findings together with striking age-dependent neurodegeneration observed in PS cDKO mice suggested that PSEN mutations might lead to $\mathrm{AD}$ as a result of partial loss of PS essential functions (Shen and Kelleher, 2007). However, it has not been tested whether partial loss of presenilin would lead to neurodegeneration in the mouse brain. In this study, we address this question by generating three groups of 
mutant mice bearing different copies of the Psen genes. We found that partial to complete loss of presenilin leads to increasingly more severe neurodegeneration, as indicated by $\sim 17 \%$ and $\sim 50 \%$ reduction of cortical volume and neuron number, respectively, in the cerebral cortex of PS1 cKO;PS2 ${ }^{+/-}$and PS1 cKO; $P S 2^{-1-}$ mice at 16 months of age. The neurodegeneration observed in these mice are accompanied by astrogliosis and microgliosis, as well as increased apoptosis. Furthermore, inactivation of PS1 leads to compensatory upregulation of PS2, which may provide protection against neurodegeneration in $P S 1 \mathrm{cKO}$ mice. Together, these findings provide direct experimental evidence showing that partial loss of PS activity indeed causes agedependent neurodegeneration in the mouse cerebral cortex.

\section{Materials and Methods}

Mice. Generation of PS1 cKO (PS1 $1^{\text {floxed/floxed }} ; P S 2^{+/+} ;$Cre $), P S$ cDKO (PS1 $\left.1^{\text {floxed/floxed }} ; P S 2^{-/-} ; C r e\right)$, and $\alpha$ CaMKII-Cre transgenic mice was described previously (Yu et al., 2001; Saura et al., 2004). To generate postnatal forebrain-specific PS1 cKO mice carrying different dosages of the $P S 2$ gene, female $P S$ cDKO mice were bred with male $P S 1^{\text {floxed/floxed }} ; P S 2^{+/+}$ mice to obtain PS1 $1^{\text {floxed/floxed }} ; P S 2^{+/-} ;$Cre and $P S 1^{\text {floxed/floxed }} ; P S 2^{+/-}$mice. Next, male mice from $P S 1^{\text {floxed/floxed }} ; P S 2^{+/+}, P S 1^{\text {floxed/floxed }} ; P S 2^{+/-}$, or $P S 1^{\text {floxed/floxed }} ; P S 2^{-/-}$mice were crossed to female $P S 1^{\text {floxed/floxed }} ; P S 2^{+/-} ;$Cre mice to obtain control $\left(P S 1^{\text {floxed/floxed }} ; P S 2^{+/+}\right.$; for histological analysis, $P S 1^{\text {floxed/floxed }} ; P S 2^{+/-}$mice were also included as control), PS1 cKO;PS2 ${ }^{+/+}$ $\left(P S 1^{\text {floxed/floxed }} ; P S 2^{+/+} ;\right.$Cre, also known as PS1 cKO), PS1 cKO;PS2 $2^{+/-}$ (PS1 $^{\text {floxed/floxed }} ; P S 2^{+/-} ;$Cre $)$, and PS1 cKO;PS2 ${ }^{-/-}\left(P S 1^{\text {floxed/floxed }} ; P S 2^{-/-}\right.$; Cre, also known as $P S \mathrm{cDKO}$ ) mice. The genetic background of all the mice used in this study was C57BL/6J 129 hybrid. For all histological analysis and stereological quantification, the experimenter was blind to the genotype of the mice. All procedures relating to animal care and treatment conformed to institutional and National Institutes of Health guidelines.

Western blot analysis. Dissected cortices (2-3, 9, or 16 months of age) were homogenized in RIPA buffer [ $50 \mathrm{~mm}$ Tris-Cl, pH 7.6, $150 \mathrm{~mm} \mathrm{NaCl}$, 0.5 mM EDTA, 1\% NP-40, 0.5\% sodium deoxycholate, 0.1\% SDS, protease inhibitor mixture (Sigma), and $1 \mathrm{~mm}$ PMSF]. Equal amounts (10-40 $\mu \mathrm{g} /$ lane) of proteins were separated in NuPAGE gels (Invitrogen) and transferred to nitrocellulose membranes. The membranes were blocked in 5\% nonfat milk/TBS for $1 \mathrm{~h}$ and incubated with specific primary antibodies as shown below: rabbit anti-PS1 (catalog \#529591 and \#529592; Calbiochem), rabbit anti-PS2 (ab51249; Abcam), rabbit anti-nicastrin (N1660; Sigma), rabbit anti-Aph-1 (PA1-2010; Pierce), rabbit anti-Pen-2 (catalog \#36-7100; Zymed), rabbit anti-amyloid precursor protein (APP; C8; kind gift from Dr. Dennis Selkoe, Center for Neurologic Diseases, Brigham and Women's Hospital and Harvard Medical School, Boston, MA), rabbit anti-amyloid precursor-like protein-1 (APLP1; catalog \#171615; Calbiochem), mouse anti-glial fibrillary acidic protein (GFAP; G6171; Sigma), and mouse anti-actin (A1978; Sigma). The membrane was then incubated with IRDye 800CW or IRDye 680-labeled secondary antibodies (LI-COR Bioscience). Signals were developed and quantified with an Odyssey Infrared Imaging System (LI-COR Bioscience).

Nissl staining. Mice were anesthetized and perfused with PBS including heparin and procaine. Brains were dissected, and hemispheres were immersed in $4 \%$ paraformaldehyde at $4^{\circ} \mathrm{C}$ for $3 \mathrm{~h}$ and then processed for paraffin embedding. Serial sagittal sections were collected by microtome at $10 \mu \mathrm{m}$ thickness. Every 40th sections were deparaffinized, dehydrated, and stained with $0.5 \%$ cresyl violet (Sigma).

Immunohistochemistry. Paraffin-embedded brain sections were deparaffinized, alcohol dehydrated, and blocked in 5\% normal goat serum/ TBS for $1 \mathrm{~h}$. Then sections were reacted with primary antibodies against NeuN (1:400; Millipore Bioscience Research Reagents), cleaved caspase-3 (1:250, Cell Signaling Technology), ionized calcium-binding adapter molecule 1 (Iba1; 1:300; Wako), or GFAP (1:500; Sigma) at $4^{\circ} \mathrm{C}$ overnight. These slides were then incubated with biotinylated secondary antibody (Vector Laboratories) at room temperature for $1 \mathrm{~h}$. Specific signals were developed by Vectastain Elite ABC kit and DAB peroxidase substrate (Vector Laboratories) and analyzed by BX40 microscope system (Olympus).

Stereological quantification. NeuN-stained sections (seven to eight sections per brain, spaced $0.4 \mathrm{~mm}$ apart) were analyzed using an unbiased fractionator and optical dissector method, and the images were analyzed using the BioQuant image analysis software that was connected to the Olympus BX51 microscope with a CCD camera. Approximately 40 optical dissectors were used for the entire neocortex area. Each optical dissector was a $100 \times 100 \mu \mathrm{m}$ sampling box, and NeuN-positive $\left(\mathrm{NeuN}^{+}\right)$neurons were counted through the $40 \times$ objective lens. The coefficient of error was $<0.10$. The volume of the neocortex was determined using Nissl-stained series sections and the BioQuant image analysis software (Yamaguchi and Shen, 2013). Values were presented as means \pm SEM.

GFAP-stained sections (five sections per brain, spaced $0.5 \mathrm{~mm}$ apart) were analyzed using the Olympus BX51 microscope with a CCD camera. The GFAP ${ }^{+}$area and the total area of the neocortex and the hippocampus were measured under $4 \times$ objective lens using the BioQuant image analysis software. The GFAP ${ }^{+}$area was determined using the set threshold value of immunostained color that covers all the GFAP signals. The percentage of $\mathrm{GFAP}^{+}$area was calculated as $\mathrm{GFAP}^{+}$area/total area $(n=$ 3-6 mice per genotype). Ibal-stained sections (five sections per brain, spaced $0.5 \mathrm{~mm}$ apart) were analyzed, and the number of $\mathrm{Iba}^{+}{ }^{+}$cells was counted using the unbiased fractionator and optical dissector method and the BioQuant image analysis software. The Iba ${ }^{+}{ }^{+}$signal was calculated as the $\mathrm{Ibal}^{+}$cell number/total area ( $n=3-6$ per genotype). All values were presented as means \pm SEMs.

Terminal deoxynucleotidyl transferase-mediated biotinylated UTP nick end labeling staining. Every 30th sections (seven to nine sections per brain) were blocked using 5\% of goat serum, 1\% BSA for $1 \mathrm{~h}$, followed by the protocol of the manufacturer of the In Situ Cell Death Detection kit (Roche). The slides were then washed using PBS for three times. Terminal deoxynucleotidyl transferase-mediated biotinylated UTP nick end labeling (TUNEL) staining was analyzed using a fluorescent microscope. $\mathrm{TUNEL}^{+}$signals in the neocortical area were counted, and the number of positive cells per section was averaged.

Data analysis. Two-tailed Student's $t$ test was conducted for all the pairwise comparisons in the biochemical results, unless stated otherwise. In Figure 6, statistical analysis was performed using one-way ANOVA, followed by post hoc analysis (Tukey's test) to measure the genotypic effect. Three to 10 mice were used per genotype group. A value of $p<$ 0.05 is considered statistically significant. All the data were reported as mean $\pm \mathrm{SEM}$, except Figure $1 C($ mean $\pm \mathrm{SD})$.

\section{Results}

\section{Neurodegeneration in the cerebral cortex of aged PS1 cKO;} $\mathrm{PS}^{+/-}$mice

Complete loss of $\gamma$-secretase activity in excitatory neurons of the cerebral cortex in presenilin $\mathrm{cDKO}$ and nicastrin $(\mathrm{Nct}) \mathrm{cKO}$ mice exhibit severe cerebral atrophy and dramatic loss of cortical volume and neurons by 6-9 months (Saura et al., 2004; Tabuchi et al., 2009; Wines-Samuelson et al., 2010). To address whether partial loss of $\gamma$-secretase activity also causes neurodegeneration in vivo, we generated $P S 1 \mathrm{cKO}$ mice carrying varying doses of the PS2 gene, in which the floxed PS1 gene is inactivated in excitatory neurons of the postnatal forebrain under control of the $\alpha$ CaMKII-Cre transgene (Yu et al., 2001; Saura et al., 2004). These mice were born at the expected ratio, and their gross appearances were normal at birth or at young adult ages.

We first performed histological analysis of postnatal forebrain-specific PS1 cKO mice carrying different dosage of the PS2 gene (PS1 cKO;PS2 ${ }^{+/+}$, PS1 $\mathrm{cKO} ; P S 2^{+/-}$, and PS1 cKO; $\left.P S 2^{-/-}\right)$and littermate control mice at $16-18$ months of age. A striking cortical atrophy was observed in the cerebral cortex of PS1 cKO;PS2 ${ }^{-/-}$mice compared with littermate controls (Fig. $1 A$ ). In addition, comparable Nissl-stained (Fig. $1 A$ ) and NeuNimmunostained (Fig. 1B) brain sections revealed a subtle atrophy 
A Nissl

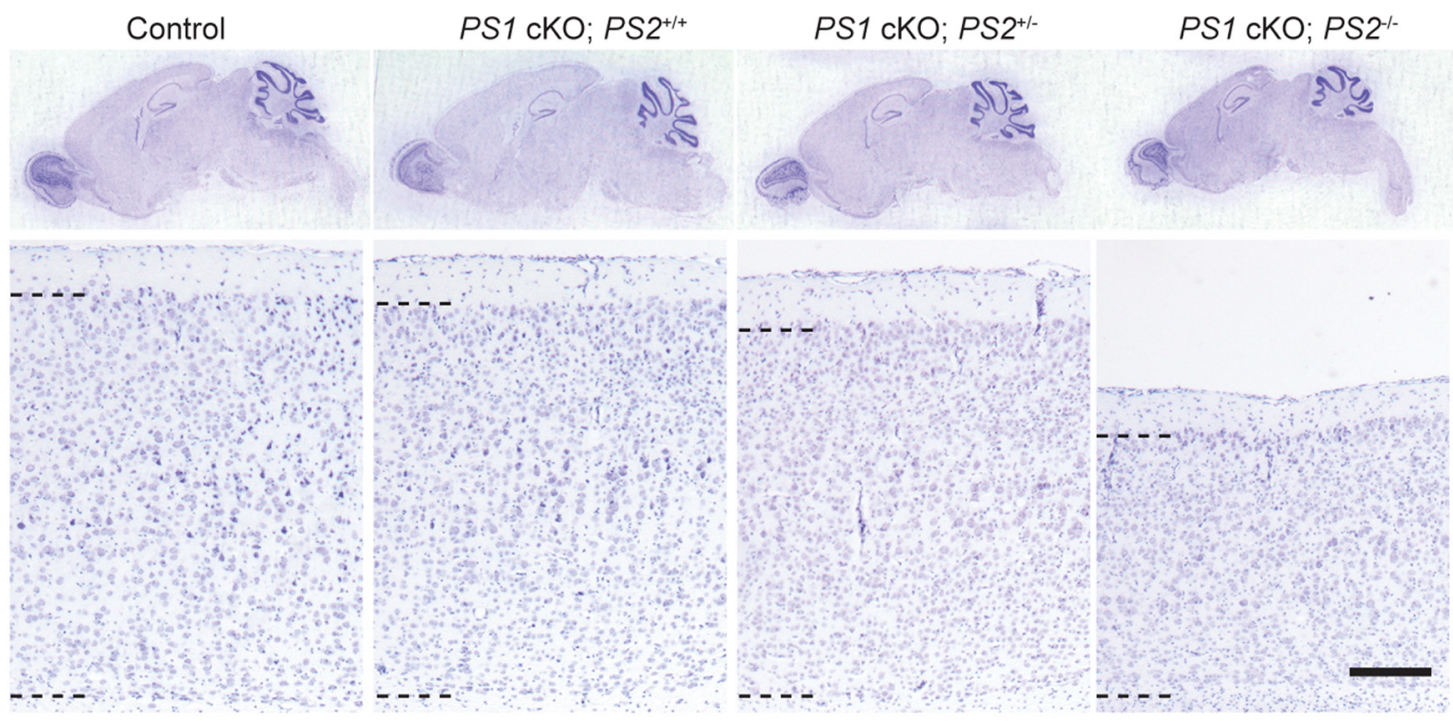

\section{B $\quad$ NeuN}

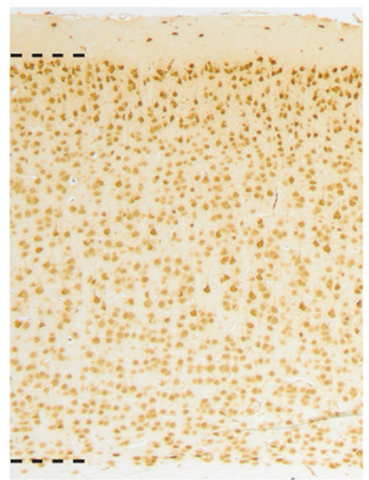

C
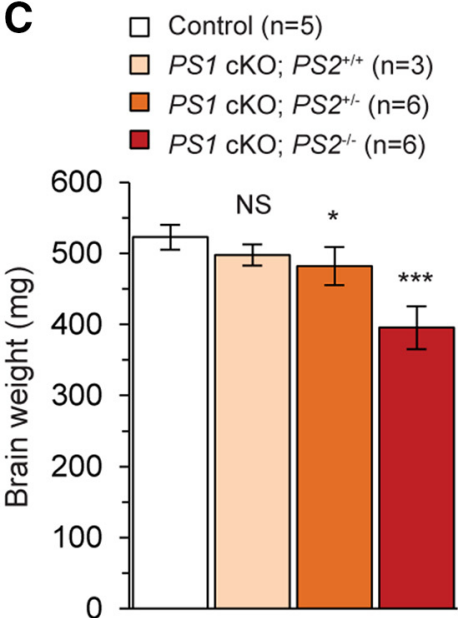

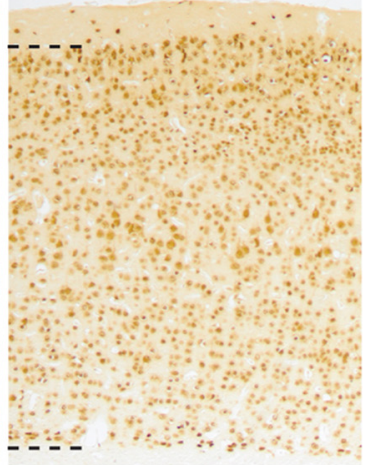

D
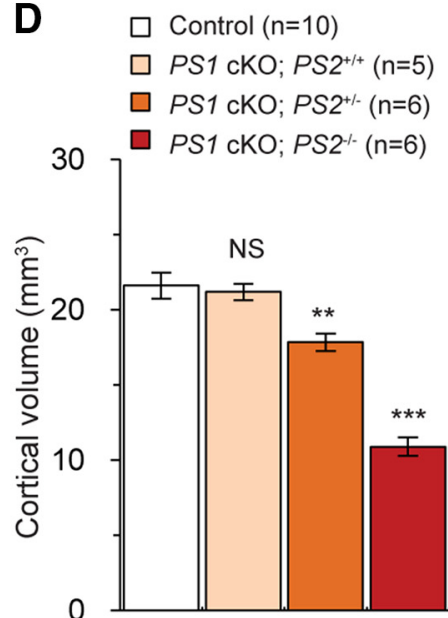

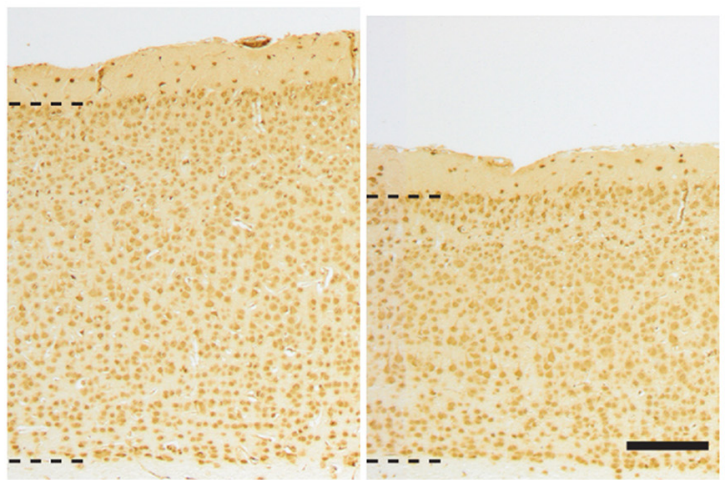

$\mathbf{E}$
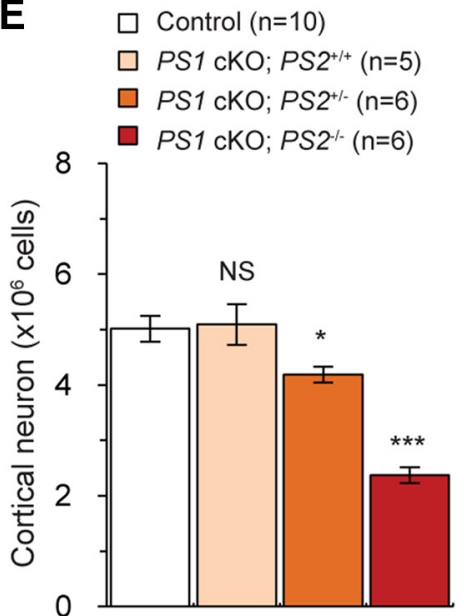

Figure 1. Neurodegeneration in the cerebral cortex of PS1 CKO;PS2 $2^{+/-}$and $P S 1 \mathrm{CKO} ; P S 2^{-/-}$mice at 16 months of age. $A$, Representative images of the Nissl-stained sagittal sections of the whole brain (top) and the neocortex (bottom) of control, PS1 CK0;PS2 ${ }^{+/+}$, PS1 CK0;PS2 ${ }^{+/-}$, and PS1 CKO;PS2 ${ }^{-/-}$mice at 16 months of age are shown. Black dashed bars delineate cortical layers II-VI. Whereas striking decreases in neocortical thickness are observed in PS1 CKO;PS2 ${ }^{-1-}$ mice, milder cortical atrophy is seen in PS1 CKO;PS2 ${ }^{+/-}$mice. Scale bar, $200 \mu \mathrm{m} . \boldsymbol{B}$, Representative images of the neocortex stained with NeuN immunoreactivity from control, PS1 CKO;PS2 ${ }^{+/+}, P S 1 \mathrm{CKO} ; P S 2^{+/-}$, and PS1 CKO;PS2 ${ }^{-/-}$mice at 16 months of age are shown. Scale bar, $200 \mu \mathrm{m}$. C $-\boldsymbol{E}$,

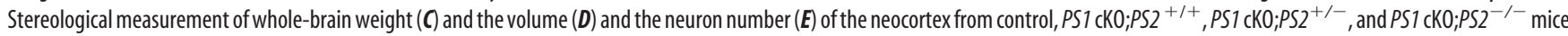
at 16 months. NS, Not significant. ${ }^{*} p<0.05 ;{ }^{* *} p<0.01 ;{ }^{* * *} p<0.001 ; n=5-10$ mice per genotype. Data are presented as the mean \pm SEM, except $\boldsymbol{C}$ (mean \pm SD). Small decreases of brain weight are present in PS1 CKO;PS2 ${ }^{+/-}$and PS1 CKO;PS2 ${ }^{-/-}$mice compared with controls. The cortical volume is significantly reduced ( $\left.\sim 17 \%\right)$ in PS1 $\mathrm{CKO}_{0} P S 2^{+/-}$mice and is further reduced in PS1 CK0;PS2 ${ }^{-/-}$mice $(\sim 50 \%)$. Values are presented as per hemisphere. Neuron numbers are also significantly decreased $(\sim 16 \%)$ in PS1 $\mathrm{cKO}^{\circ}$ PS2 ${ }^{+/-}$mice and are further decreased in PS1 cKO;PS2 ${ }^{-1-}$ mice ( $\left.\sim 52 \%\right)$. 

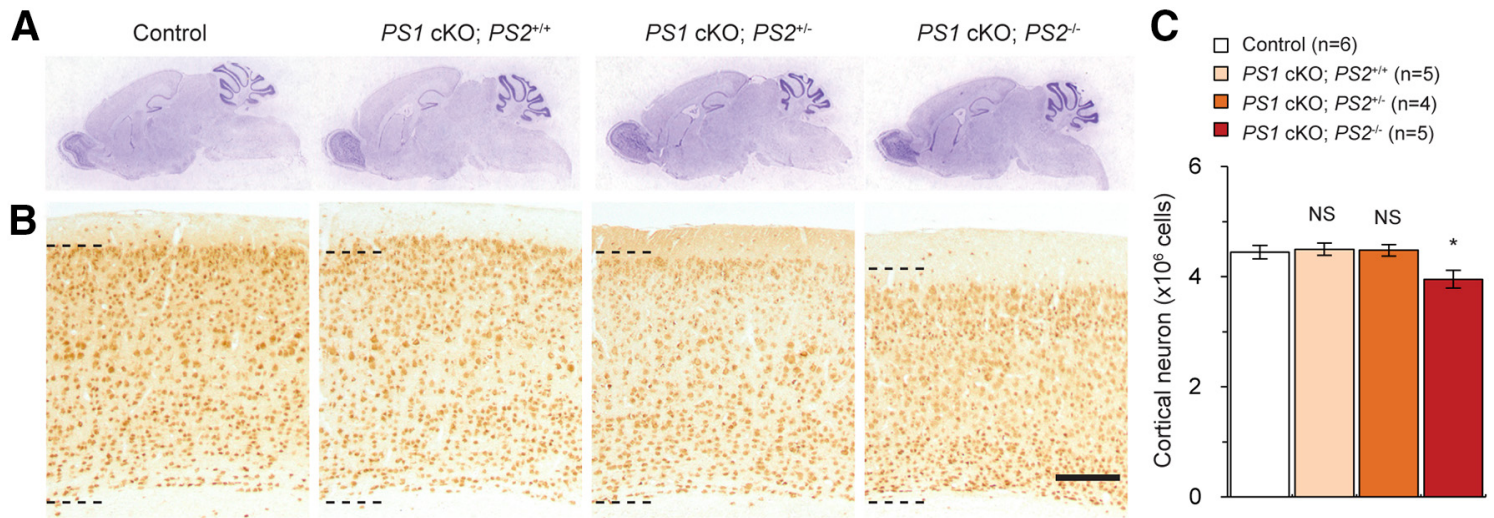

Figure 2. No significant reduction of cortical neuron number in the neocortex of $P S 1 \mathrm{CKO} ; P S 2^{+/-}$mice at 4 months of age. $A$, Representative images of the Nissl-stained sagittal sections of control, PS1 CK0;PS2 ${ }^{+/+}, P S 1 \mathrm{CKO} ; P S 2^{+/-}$, and PS1 CK0;PS2 ${ }^{-/-}$mice at 4 months of age are shown. $B$, Representative images of the neocortex stained with NeuN immunoreactivity from control, PS1 CK0;PS2 ${ }^{+/+}$,PS1 CK0;PS2 ${ }^{+/-}$, and PS1 CK0;PS2 ${ }^{-/-}$mice at 4 months of age are shown. Black dashed bars delineate cortical layers II-VI. Cortical atrophy is seen at this age in PS1 CK0;PS2 ${ }^{-/-}$ mice. Scale bar, $200 \mu \mathrm{m}$. C, Stereological measurement of neuron number in the neocortex from control, PS1 CK0;PS2 ${ }^{+1+}$, PS1 cK0;PS2 ${ }^{+/-}$, and PS1 CK0;PS2 ${ }^{-1-}$ mice at 4 months shows significant reduction $(\sim 11 \%)$ of neuron number in PS1 CK0;PS2 ${ }^{-/-}$mice relative to controls, whereas no cortical neuron loss is detected in PS1 cK0;PS2 ${ }^{+/-}$mice. NS, Not significant. ${ }^{*} p<0.05$; $n=4-6$ mice per genotype. Data are presented as the mean \pm SEM.

of the neocortex in the brain of PS1 $\mathrm{cKO} ; P S 2^{+/-}$mice compared with littermate controls, as well as small reduction of whole-brain weight (Fig. 1C). To examine the subtle cortical atrophy of PS1 $\mathrm{cKO} ; P S 2^{+1-}$ mice thoroughly, we next performed unbiased quantitative stereological analysis using Nissl-stained series brain sections. Compared with littermate controls, a marked reduction of neocortical volume was observed in PS1 cKO;PS2 $2^{+/-}(\sim 17 \%$; $p=0.005)$ and PS1 cKO;PS2 ${ }^{-/-}\left(\sim 50 \% ; p=2.423 \times 10^{-7}\right)$ mice, respectively (Fig. $1 D$; control, $21.65 \pm 0.86 \mathrm{~mm}^{3}$; $P S 1 \mathrm{cKO}$; $P S 2^{+/-}, 17.85 \pm 0.58 \mathrm{~mm}^{3} ; P S 1 \mathrm{cKO} ; P S 2^{-/-}, 10.91 \pm 0.60$ $\mathrm{mm}^{3}$ ), whereas no obvious change was seen in PS1 cKO;PS2 ${ }^{+/+}$ mice $\left(21.21 \pm 0.55 \mathrm{~mm}^{3}, p=0.740\right)$. Likewise, as measured by counting $\mathrm{NeuN}^{+}$cells, the number of neocortical neurons was significantly decreased by $\sim 16.4 \%(p=0.019)$ and $\sim 52.4 \%$ ( $p=$ $\left.6.554 \times 10^{-7}\right)$ in $P S 1 \mathrm{cKO} ; P S 2^{+/-}$and PS1 $\mathrm{cKO} ; P S 2^{-/-}$mice, respectively (Fig. $1 E$; control, $5.02 \times 10^{6}$ cells; PS1 $\mathrm{cKO}^{2} P S 2^{+/-}$, $4.19 \times 10^{6}$ cells; $P S 1 \mathrm{cKO} ; P S 2^{-1-}, 2.37 \times 10^{6}$ cells), whereas no obvious change was seen in PS1 cKO;PS2 ${ }^{+/+}$mice $\left(5.09 \times 10^{6}\right.$ cells, $p=0.854$ ). These results show that partial loss of PS dosage also results in cortical atrophy and cortical neuronal loss in PS1 $\mathrm{CKO} ; P S 2^{+/-}$mice, although the extent of neurodegeneration is less severe compared with PS1 $\mathrm{cKO} ; \mathrm{PS}^{-/-}$mice.

We further performed similar stereological analysis at 4 months of age and found no reduction of cortical volume in PS1 cKO;PS $2^{+/-}$mice (Fig. $2 A$; control, $21.78 \pm 0.62 \mathrm{~mm}^{3} ; P S 1 \mathrm{cKO}$; $\left.P S 2^{+/-}, 20.97 \pm 1.62 \mathrm{~mm}^{3}, p=0.604\right)$. Using NeuN-stained series sections, we also did not see alteration of cortical neuron number in $P S 1 \mathrm{cKO} ; P S 2^{+/-}$mice at this age (Fig. $2 \mathrm{~B}, C$; control, $4.45 \times 10^{6} ;$ PS1 cKO;PS2 $\left.{ }^{+/-}, 4.48 \times 10^{6}, p=0.853\right)$, whereas $\sim 11 \%$ reduction of cortical neuron number was observed in PS1 $\mathrm{CKO} ; P S 2^{-1-}$ mice at this age, as we reported previously (WinesSamuelson et al., 2010). Together, these results show the later age of onset for neurodegeneration in PS1 cKO;PS2 ${ }^{+/-}$mice relative to $P S 1 \mathrm{cKO} ; P S 2^{-1-}$ mice.

\section{Increased apoptosis in PS1 cKO;PS2 ${ }^{+/-}$mice}

Previous studies showed increases of neuronal apoptosis as early as 2 months of age in the cerebral cortex of PS1 cKO;PS2 ${ }^{-1-}$ mice (Wines-Samuelson et al., 2010). To determine whether apoptosis is increased in the cerebral cortex of PS1 cKO;PS2 $2^{+/-}$mice, we performed immunostaining using antibodies specific for active (cleaved) forms of caspase-3, which is an excellent marker for apoptosis (Earnshaw et al., 1999). Similar to the previous report (Wines-Samuelson et al., 2010), significant increases of cells positive for active caspase-3 were found in the neocortex of PS1 $\mathrm{cKO} ; P S 2^{-1-}$ mice at 4 months of age relative to controls (Fig. $3 A$; control, $3.35 \pm 0.48 ;$ PS1 cKO;PS2 ${ }^{-/-}$, $9.71 \pm 1.62$ cells per section, $p=0.020$ ), whereas at 16 months, the increase of active caspase- $3^{+}$cells in the PS1 cKO;PS2 ${ }^{-1-}$ neocortex is not significant compared with the control (control, $2.95 \pm 0.44 ; P S 1 \mathrm{cKO}$; $P S 2^{-/-}, 4.21 \pm 1.30$ cells per section, $p=0.274 ; n=6-11$ ). Interestingly, the number of cells positive for active caspase- 3 was increased in PS1 cKO;PS2 ${ }^{+/-}$mice compared with littermate controls at 16 months of age (Fig. $3 A ; 7.08 \pm 1.09$ cells per section, $\left.p=7.872 \times 10^{-4}\right)$ but not at 4 months $(4.21 \pm 0.27$ cells per section, $p=0.191)$. In contrast, $P S 1 \mathrm{cKO} ; P S 2^{+/+}$mice did not exhibit a significant change in the number of cells positive for active caspase- 3 ( 4 months, $3.04 \pm 0.42$ cells per section, $p=$ $0.658 ; 16$ months, $3.73 \pm 1.23$ cells per section, $p=0.465)$. These results indicate that neuronal cell death occurs in the cerebral cortex of PS1 cKO;PS2 ${ }^{+/-}$mice, but the age of onset of apoptosis is delayed in the cerebral cortex of $P S 1 \mathrm{cKO} ; P S 2^{+/-}$mice compared with $P S 1 \mathrm{cKO} ; P S 2^{-/-}$mice.

To confirm further the occurrence of apoptosis in the cortex of PS1 cKO;PS2 $2^{+/-}$mice, we also performed the TUNEL assay using mice at 16 months of age, in which PS1 cKO;PS2 ${ }^{+/-}$mice exhibit significant increases of active caspase- 3 signals. Similarly, we found a significant increase in the number of TUNEL ${ }^{+}$cells in the neocortex of PS1 cKO;PS2 ${ }^{+/-}$mice at 16 months $(p=0.005)$ compared with control mice (Fig. $3 B$; TUNEL $^{+}$cells per section: control, $0.41 \pm 0.12 ; P S 1 \mathrm{cKO}^{\circ} P S 2^{+/+}, 0.59 \pm 0.26 ; P S 1 \mathrm{cKO}$; $P S 2^{+/-}, 1.89 \pm 0.51 ; n=3-6$ ) but not at 4 months (control, $0.39 \pm 0.20 ;$ PS $1 \mathrm{cKO} ; P S 2^{+/-}, 0.78 \pm 0.06$ per section, $p=$ $0.135)$. TUNEL $^{+}$cells are also increased in the cerebral cortex of $P S 1 \mathrm{cKO} ; P S 2^{-/-}$mice at 16 months of age $(1.19 \pm 0.25$ cells per section, $p=0.011$ ), although the increase of apoptosis is greater at 4 months of age $(15.83 \pm 1.90$ cells per section, $p=1.260 \times$ $\left.10^{-3}\right)$. Together, these results suggest that apoptotic cell death occurs in the neocortex of both PS1 cKO;PS2 ${ }^{+/-}$and PS1 cKO; $P S 2^{-1-}$ mice, although the age of onset is later in $P S 1 \mathrm{cKO}$; $P S 2^{+/-}$mice with increases of apoptosis occurring at 16 months 


\section{A Cleaved Caspase 3}

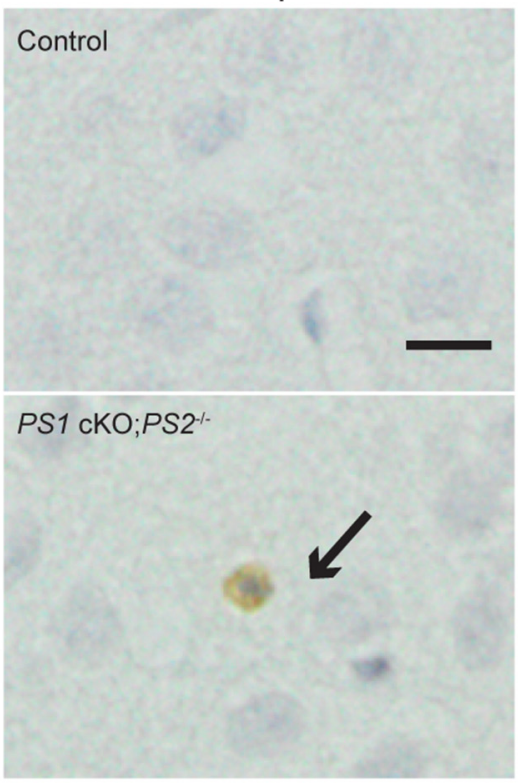

B
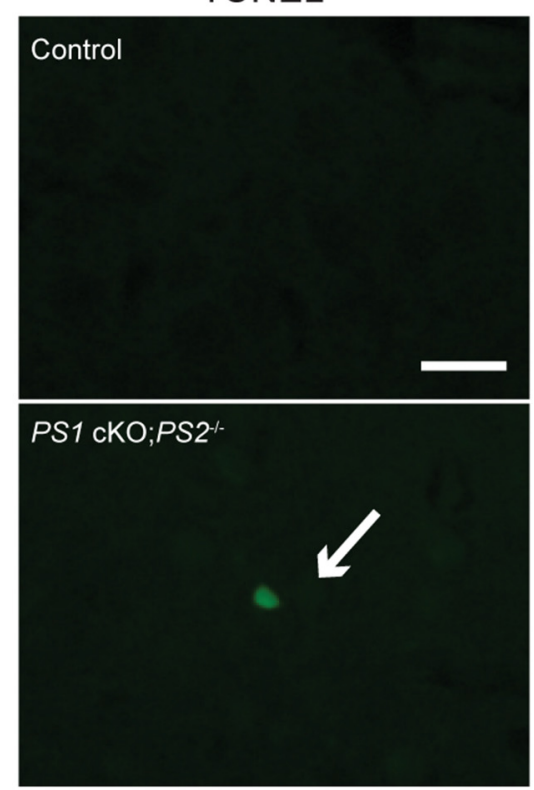

4-month

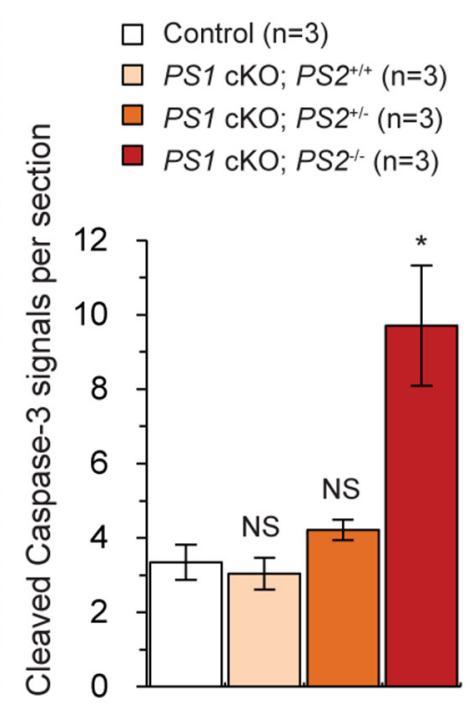

4-month

Control $(n=3)$

$\square P S 1 \mathrm{cKO} ; \mathrm{PS2}^{+/+}(\mathrm{n}=3)$

$\square P S 1 \mathrm{cKO} ; P S 2^{+/-}(\mathrm{n}=3)$

$\square P S 1 \mathrm{cKO} ; P S 2^{-/}(\mathrm{n}=3)$

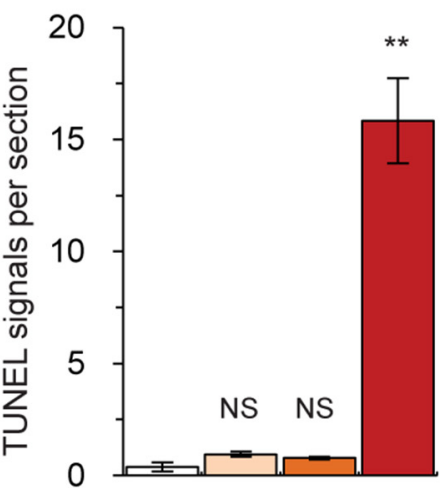

16-month

$\square$ Control $(\mathrm{n}=11)$

$\square$ PS1 cKO; $P S 2^{+/+}(\mathrm{n}=5)$

$\square P S 1 \mathrm{cKO} ; P S 2^{+/-}(\mathrm{n}=6)$

PS1 cKO; PS2 ${ }^{-/}(\mathrm{n}=6)$

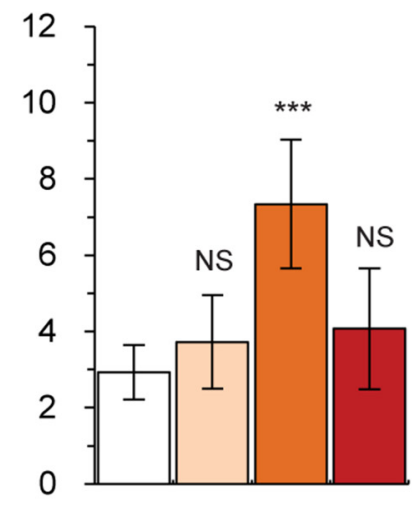

16-month
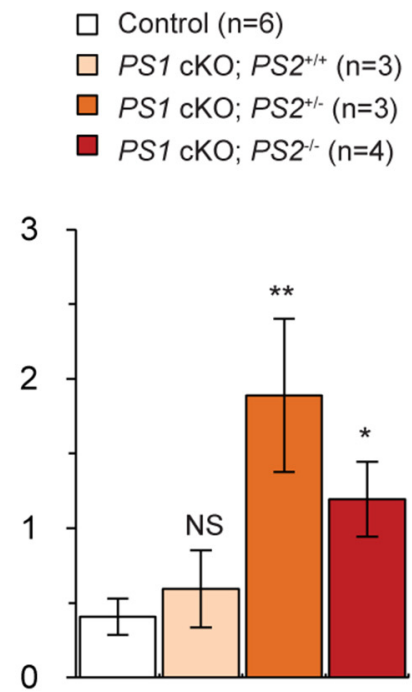

Figure 3. Delayed onset of apoptosis in the cerebral cortex of $P S 1 \mathrm{CKO} ; P S 2^{+/-}$mice relative to $P S 1 \mathrm{CKO} ; P S 2^{-/-}$mice. $A$, Quantification of cells positive for activated caspase-3. Left, Representative optical micrographs are indicated from control (top) and PS1 CKO;PS2 ${ }^{-1-}$ (bottom) mice. Right, The number of active caspase- $3^{+}$cells is significantly increased in the neocortex of PS1 CK0;PS2 ${ }^{+/-}$mice at 16 months of age but not at 4 months $(n=3-11$ mice per genotype per age; $8-9$ sections analyzed per mouse). Data are presented as the mean \pm SEM. $\boldsymbol{B}$, Left, Fluorescent microscopic images of TUNEL ${ }^{+}$cells in the neocortex of control (top) and PS1 CKO;PS2 ${ }^{-1-}$ (bottom) mice. Right, Quantification of TUNEL ${ }^{+}$cells shows considerable increases in the PS1 CK0;PS2 ${ }^{+/-}$neocortex at 16 months compared with controls ( $n=3-6$ mice per genotype; 9 sections analyzed per mouse) but not at 4 months. Scale bar, $20 \mu \mathrm{m}$. NS, Not significant. ${ }^{*} p<0.05$; ${ }^{* *} p<0.01 ;{ }^{* * *} p<0.001$. Data are presented as the mean \pm SEM.

in $P S 1 \mathrm{cKO} ; P S 2^{+/-}$mice and at 4 months in PS1 $\mathrm{cKO} ; P S 2^{-/-}$ mice.

\section{Progressive gliosis in PS1 cKO;PS2 ${ }^{+/-}$mice}

Because resident astrocytes are activated with ongoing neurodegeneration (Beglopoulos et al., 2004; Saura et al., 2004; Lobsiger and Cleveland, 2007; Heneka et al., 2010), we next looked for the presence of astrogliosis, as performed by immunohistochemical analysis on GFAP, a marker of astrogliosis, using brain sections of PS1 cKO;PS2 ${ }^{+/-}$mice and littermate controls. As expected, we did not detect increases of GFAP immunoreactivity in the hip- pocampus and the neocortex in $P S 1 \mathrm{cKO} ; P S 2^{+/+}$mice at both 4 and 16 months of age, whereas we could easily see robust increases of GFAP immunoreactivity in PS1 cKO;PS2 ${ }^{-/-}$mice even at 4 months (Fig. $4 A, B$ ), when prominent apoptosis had taken place in the cerebral cortex (Fig. 3). Interestingly, moderate increases of GFAP signals were detected in $P S 1 \mathrm{cKO} ; \mathrm{PS}^{+/-}$mice at 16 months of age but not 4 months of age (Fig. $4 A, B$ ). To determine the extent of astrogliosis further, we performed unbiased stereological quantification of GFAP signals in the neocortex and hippocampus (percentage $\mathrm{GFAP}^{+}$area/tissue area). GFAP signals are unaltered in the neocortex (control, $1.01 \pm$ 
A 4 months
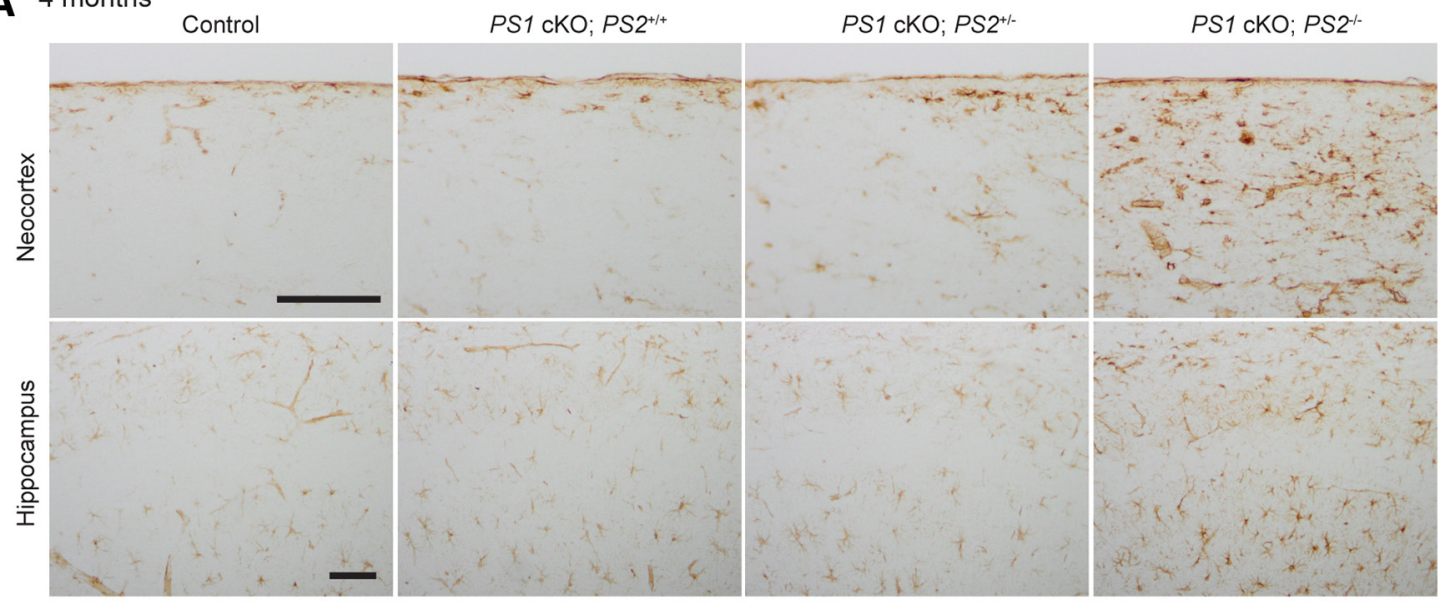

B 16 months
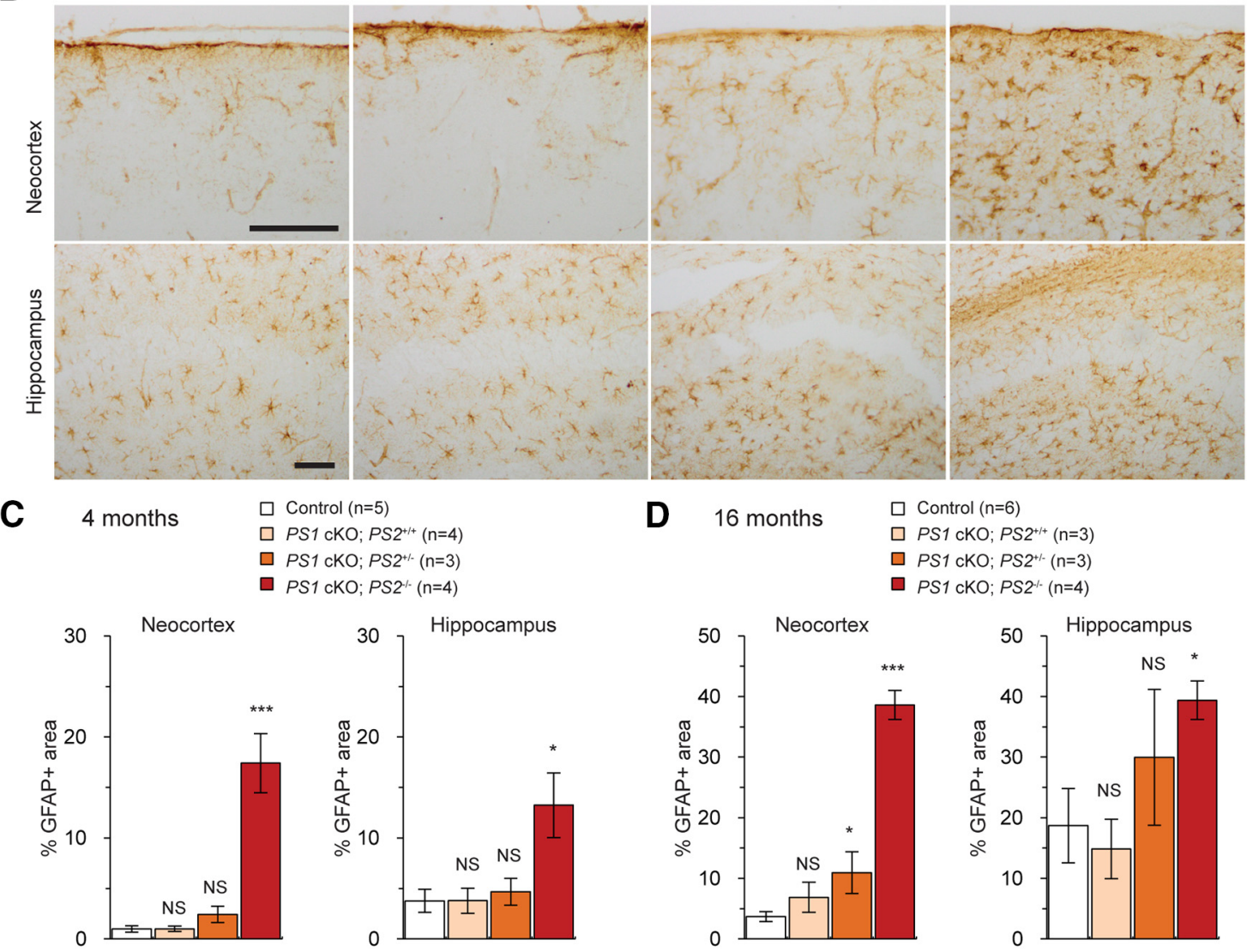

D 16 months

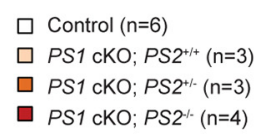

Figure 4. Astrogliosis in the cerebral cortex of PS1 $\mathrm{CK0} ; P S 2^{+/-}$and $P S 1 \mathrm{CKO} ; P S 2^{-/-}$mice at 16 months. $A, B$, Immunostaining of GFAP in the neocortex and hippocampus from each genotype at $4(\boldsymbol{A})$ and $16(\boldsymbol{B})$ months of age. There is a progressive astrogliosis in PS1 CKO;PS2 ${ }^{+-}$and PS1 CKO;PS2 ${ }^{-/-}$mice. Scale bar, $100 \mu \mathrm{m}$. $\boldsymbol{C}$, Stereological measurement of GFAP ${ }^{+}$areas from the neocortex (left) and the hippocampus (right) at 4 months of age ( $n=3-5$ mice per genotype; 5 sections analyzed per mouse) shows a significant increase of GFAP signals in the neocortex and hippocampus of PS1 CKO;PS2 ${ }^{-1-}$ mice but not in PS1 CK0;PS2 ${ }^{+-}$mice. D, Stereological measurement of GFAP ${ }^{+}$areas from the neocortex (left) and the hippocampus (right) at 16 months of age ( $n=3-6$ mice per genotype; 5 sections analyzed per mouse) shows a significant increase of GFAP signals in the neocortex of PS1 CK0;PS2 ${ }^{+-}$mice, whereas there is greater variability in GFAP signals in the hippocampus. NS, Not significant. ${ }^{*} p<0.05 ;{ }^{* * *} p<0.001$. Data are presented as the mean \pm SEM.

$\left.0.31 \% ; P S 1 \mathrm{cKO} ; P S 2^{+/-}, 2.43 \pm 0.80 \% ; p=0.096\right)$ and the hippocampus (control, $3.77 \pm 1.14 \% ; P S 1 \mathrm{cKO} ; P S 2^{+/-}$, $4.67 \pm 1.33 \% ; p=0.634)$ of $P S 1 \mathrm{cKO} ; P S 2^{+/-}$mice at 4 months (Fig. $4 C$ ), but GFAP signals are significantly increased in the neocortex of PS1 cKO;PS2 $2^{+/-}$mice at 16 months of age (Fig. $4 D$, left; control, $3.68 \pm 0.82 \%$; PS1 cKO;PS2 ${ }^{+/-}, 10.94 \pm$ $3.42 \% ; p=0.0247)$. However, we did not see significant increases of GFAP in the hippocampus of PS1 cKO;PS2 $2^{+/-}$mice at 16 months (Fig. 4D, right; control, $18.72 \pm 6.13 \%$; PS1 cKO;PS2 $\left.2^{+/-}, 29.98 \pm 11.20 \% ; p=0.3636\right)$, perhaps because of the higher and more variable basal GFAP signals in the hippocampus of control mice at this age (Fig. $4 B, D$ ). PS1 cKO;PS $2^{+/+}$mice did not exhibit any alteration at 4 months (neocortex, $1.00 \pm 0.52 \%, p=0.987$; hippocampus, $3.79 \pm$ $1.24 \%, p=0.991$ ) or 16 months (neocortex, $6.86 \pm 2.48 \%$, $p=0.160$; hippocampus, $14.84 \pm 4.91 \%, p=0.696)$. These 


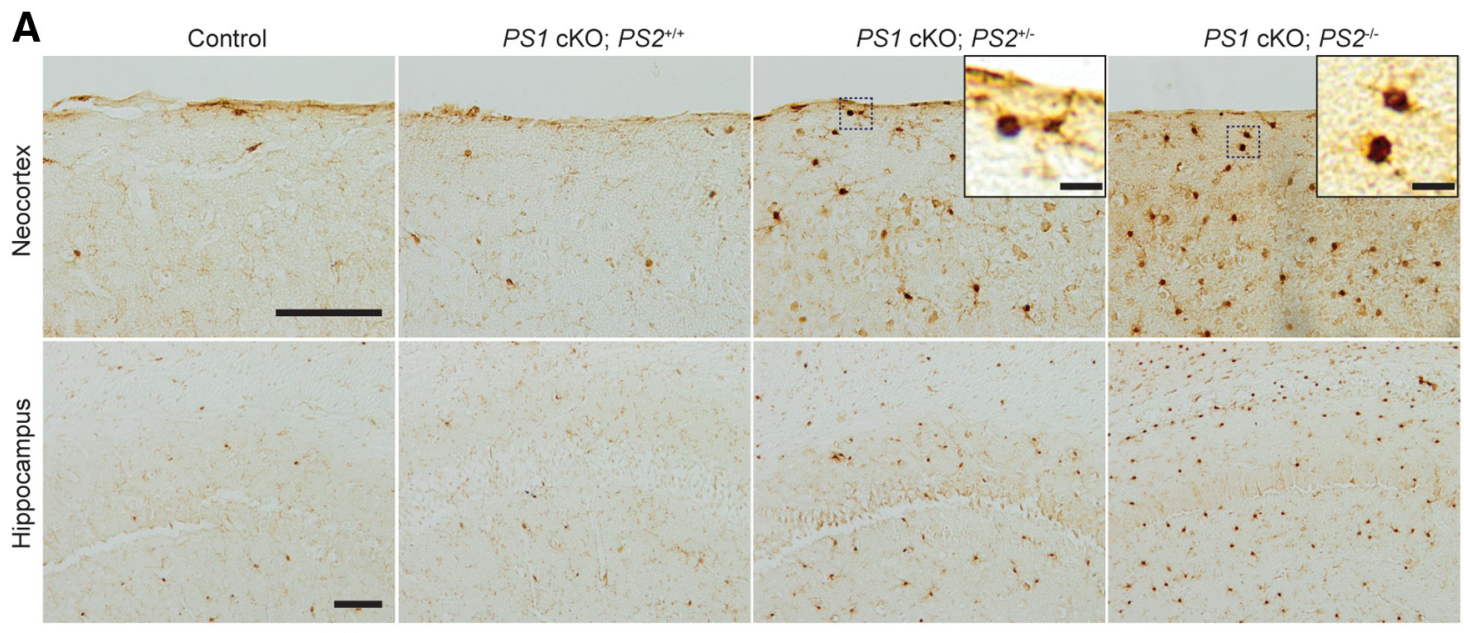

B
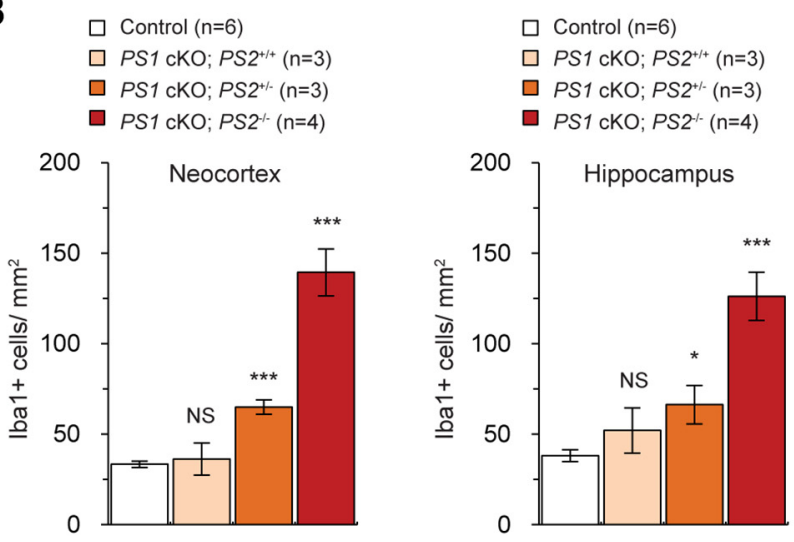

Figure 5. Microgliosis in the cerebral cortex of $P S 1 \mathrm{CKO} ; P S 2^{+/-}$and $P S 1 \mathrm{CKO} ; P S 2^{-/-}$mice at 16 months. $A$, Iba1 immunoreactivity appears higher in the neocortex and hippocampus of $P S 1$ CK0;PS2 ${ }^{+/-}$mice and further increased in PS1 CK0;PS2 ${ }^{-1-}$ mice. The insets in the pictures show higher-magnification views of the lba ${ }^{+}$cells. Scale bars, $100 \mu \mathrm{m}$; insets $10 \mu \mathrm{m} . \boldsymbol{B}$, Stereological quantification of $\mathrm{lba}^{+}$cells from the neocortex (left) and the hippocampus (right) at 16 months of age ( $n=3-6$ mice per genotype; $4-5$ sections analyzed per mouse) shows a significant increase of Iba ${ }^{+}$cells in the neocortex and hippocampus of PS1 CKO;PS2 ${ }^{+/-}$and PS1 CKO;PS2 ${ }^{-/-}$mice. NS, Not significant. ${ }^{*} p<0.05 ;{ }^{* * *} p<0.001$. Data are presented as the mean \pm SEM.

results show an incidence of mild astrogliosis accompanying neurodegeneration in $P S 1 \mathrm{cKO} ; P S 2^{+/-}$mice.

We next performed immunohistochemical analysis on Ibal, which is specifically expressed in microglia in the brain. We found that Ibal immunoreactivity was increased in PS1 $\mathrm{cKO} ; P S 2^{+/-}$and $P S 1 \mathrm{cKO} ; P S 2^{-1-}$ mice at 16 months of age but not in PS1 cKO;PS2 ${ }^{+/+}$mice (Fig. $5 A$ ). Unbiased stereological quantification uncovered significant increases of Ibal signals (Iba ${ }^{+}$cell number/tissue area) in the neocortex (control, $33.45 \pm 1.79$ cells $/ \mathrm{mm}^{2} ;$ PS1 cKO;PS2 ${ }^{+/-}, 64.96 \pm 3.99$ cells $/ \mathrm{mm}^{2} ; p=6.107 \times 10^{-5}$ ) and the hippocampus (control, $38.24 \pm 3.26$ cells $/ \mathrm{mm}^{2} ; P S 1 \mathrm{cKO} ; P S 2^{+/-}, 66.36 \pm 10.57$ cells/ $\left.\mathrm{mm}^{2} ; p=0.012\right)$ of $P S 1 \mathrm{cKO} ; P S 2^{+/-}$mice compared with littermate controls at 16 months of age (Fig. $5 B$ ), whereas robust increases were observed in PS1 cKO;PS2 ${ }^{-1-}$ mice (neocortex, $139.39 \pm 12.93$ cells $/ \mathrm{mm}^{2}, p=7.726 \times 10^{-6}$; hippocampus, $\left.126.07 \pm 13.31 \mathrm{cells} / \mathrm{mm}^{2}, p=5.326 \times 10^{-5}\right)$. In contrast, $P S 1 \mathrm{cKO} ; P S 2^{+/+}$mice did not exhibit any alteration (neocortex, $36.35 \pm 8.81$ cells $/ \mathrm{mm}^{2}, p=0.662$; hippocampus, $52.16 \pm 12.49$ cells $\left./ \mathrm{mm}^{2}, p=0.185\right)$ relative to controls. Together, PS1 cKO;PS2 ${ }^{+-}$mice exhibit modest gliosis in both astrocytes and microglia accompanied by neuronal cell death, but these phenotypes are less severe than that in cerebral cortex of PS1 cKO;PS2 ${ }^{-/-}$mice.

\section{Upregulation of PS2 in the cerebral cortex of PS1 cKO;PS2 ${ }^{+/+}$and $P S 1 \mathrm{cKO} ; P 2^{+/-}$mice}

To determine whether levels of PS1, PS2, and other components of the $\gamma$-secretase complex were altered, we performed Western blot analysis using cell lysates isolated from the cerebral cortex of $P S 1 \mathrm{cKO} ; P S 2^{+/+}, P S 1 \mathrm{cKO} ; P S 2^{+/-}, P S 1 \mathrm{cKO} ; P S 2^{-/-}$, and littermate control mice at 2 months of age. We found similar reductions $(\sim 60 \%)$ of PS1 N-terminal fragments (NTFs) and $\mathrm{C}$-terminal fragments (CTFs) in the cerebral cortex of PS1 cKO; $\mathrm{PS}^{+/+}, \mathrm{PS} 1 \mathrm{cKO} ; \mathrm{PS}^{+/-}$, and PS1 $\mathrm{cKO} ; \mathrm{PS}^{-/-}$mice compared with littermate controls (Fig. 6). An overall ANOVA showed significant genotypic effect between controls and other genotypes (NTFs, $F_{(3,12)}=222.9, p<0.0001$; CTFs, $F_{(3,12)}=90.84, p<$ 0.0001 ), but there was no difference by post hoc test among PS1 $\mathrm{cKO} ; P S 2^{+/+}, P S 1 \mathrm{cKO} ; P S 2^{+/-}$, and PS1 cKO;PS2 ${ }^{-/-}$mice. Interestingly, PS2 CTFs were increased by $\sim 30 \%$ in the cerebral cortex of $P S 1 \mathrm{cKO} ; P S 2^{+/+}$compared with littermate controls, suggesting compensatory upregulation attributable to the lack of PS1 protein, consistent with other reports (Dewachter et al., 2002; Lai et al., 2003). The compensatory upregulation of PS2 was also observed at a similar extent at 16 months of age (data not shown), suggesting that this increase is consistent from 2 to 16 months of age. Compared with PS1 cKO;PS2 ${ }^{+/+}$mice, levels of PS2 CTFs were decreased by $50 \%$ in the cerebral cortex of PS1 cKO; $\mathrm{PS}^{+/-}$mice and completely eliminated in PS1 $\mathrm{cKO} ; \mathrm{PS}^{-/-}$mice. 

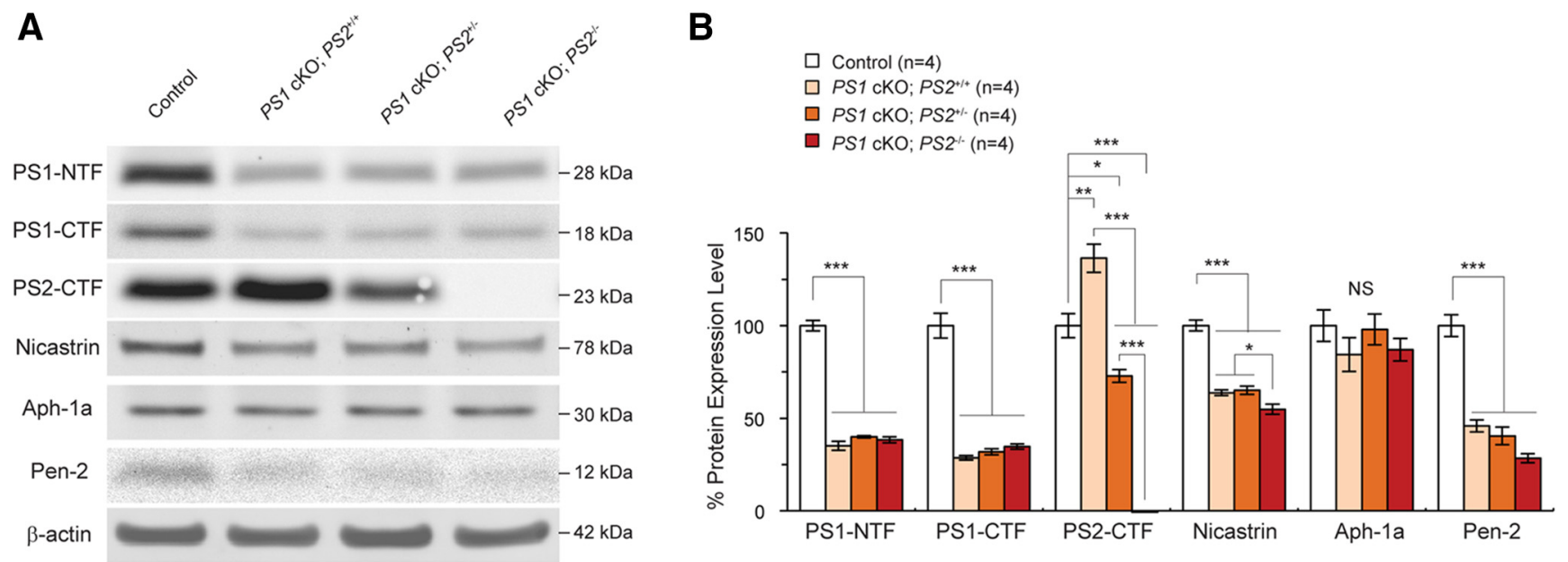

Figure 6. Upregulation of PS2 in the cerebral cortex of PS1 CK0;PS2 ${ }^{+/+}$and PS1 CK0;PS2 ${ }^{+/-}$mice. $A$, Western blot analysis of PS1 NTF, PS1 CTF, PS2 CTF, nicastrin, Aph-1a, Pen-2, and $\beta$-actin. Representative blots are shown for each protein. B, Quantitative analysis of control, $P S 1 \mathrm{CKO} ; P S 2^{+/+}, P S 1 \mathrm{CKO} ; P S 2^{+/-}$, and $P S 1 \mathrm{CKO} ; P S 2^{-/-}$mouse brains at 2 months of age $(n=4$ per genotype) shows $\sim 60 \%$ decreases of NTFs and CTFs of PS1 in PS1 CKO;PS2 ${ }^{+/+}, P S 1 \mathrm{CKO} ; P S 2^{+/-}$, and PS1 $\mathrm{CKO} ; P S 2^{-/-}$at 2 months of age ( $n=4$ per genotype). PS2 CTFs are increased by $\sim 30 \%$ in cortical lysates of PS1 CK0;PS2 ${ }^{+/+}$and PS1 CK0;PS2 ${ }^{+/-}$mice compared to the expected values, suggesting compensatory upregulation in the absence of PS1. Levels of nicastrin and Pen-2 are decreased by $\sim 40 \%$ and $\sim 60 \%$ in the mutant mice compared with controls, respectively, whereas levels of another $\gamma$-secretase component, Aph-1a, is present at comparable levels between the genotypic groups. NS, Not significant. ${ }^{*} p<0.05 ;{ }^{* *} p<0.01 ;{ }^{* * *} p<0.001$. All data are expressed as mean \pm SEM.

Given the fact that PS1 is inactivated selectively in excitatory neurons but not in interneurons and glia, which is consistent with the $\sim 40 \%$ PS1 protein remaining in the cortical lysates of PS1 cKO mice, the increase of PS2 levels in excitatory neurons is likely to be greater than the $30 \%$ increase detected in total cortical lysates of PS1 cKO mice (Fig. 6). Thus, the compensatory upregulation of PS2 in PS1 $\mathrm{cKO} ; P S 2^{+/+}$and $P S 1 \mathrm{cKO} ; P S 2^{+/-}$mice likely protect the excitatory neurons during aging.

We further quantified other components of the $\gamma$-secretase complex. For quantification of nicastrin, we first treated peptide$\mathrm{N}$-glycosidase $\mathrm{F}$ to remove saccharide groups from the mature glycosylated form of nicastrin proteins and then performed Western blot analysis. Levels of nicastrin and Pen-2 proteins were significantly reduced in the cortical lysates from PS1 cKO; $P S 2^{+/+}, P S 1 \mathrm{cKO} ; P S 2^{+/-}$, and PS1 $\mathrm{cKO} ; P S 2^{-/-}$mice at 2 months of age compared with littermate controls (Fig. 6; nicastrin, $F_{(3,12)}=68.74, p<0.0001$; Pen-2, $F_{(3,12)}=54.92, p<$ $0.0001)$. Conversely, Aph-1a protein was unchanged among all four genotypes $\left(F_{(3,12)}=0.931, p=0.456\right)$, consistent with our previous findings in nicastrin cKO mice (Tabuchi et al., 2009). These data show that loss of PS1 disrupts the $\gamma$-secretase complex, resulting in reduction of nicastrin and Pen-2 in the cortex of $P S 1 \mathrm{cKO} ; P S 2^{+/+}, P S 1 \mathrm{cKO} ; P S 2^{+/-}$, and PS1 $\mathrm{cKO} ; P S 2^{-/-}$mice.

\section{Decreased $\gamma$-secretase activity in the cerebral cortex of PS1 cKO;PS2 ${ }^{+/-}$mice}

We next evaluated $\gamma$-secretase activity by measuring levels of the APP CTFs, because accumulation of APP CTFs is a sensitive marker for impairment of $\gamma$-secretase activity in mouse brains (Yu et al., 2001; Dewachter et al., 2002; Saura et al., 2004; Saura et al., 2005). We performed Western blot analysis to measure levels of APP CTFs in the cortex of PS1 CKO;PS2 ${ }^{+/+}, P S 1 \mathrm{cKO} ; \mathrm{PS}^{+/-}$, and $P S 1 \mathrm{cKO} ; P S 2^{-/-}$mice, as well as the littermate controls. We found dramatic accumulation ( $\sim 30$-fold) of APP CTFs in the cortex of $P S 1 \mathrm{cKO} ; P S 2^{+/+}$mice (Fig. $7 A$ ). Interestingly, the extent of the accumulation is inversely correlated with the dosage of the PS2 gene in PS1 cKO mice (Fig. 7A). Compared with PS1 $\mathrm{cKO} ; P S 2^{+/+}$mice, levels of APP CTFs are increased significantly by $\sim 1.2$-fold $\left(p=2.225 \times 10^{-2}\right)$ and $\sim 2$-fold $(p=9.352 \times$
$10^{-6}$ ) in PS1 cKO;PS2 ${ }^{+/-}$and PS1 cKO;PS2 ${ }^{-/-}$mice at 2 months, respectively. Likewise, its accumulation is increased significantly by $\sim 1.5$-fold $\left(p=1.927 \times 10^{-3}\right)$ and $\sim 2.2$-fold $(p=$ $\left.6.555 \times 10^{-4}\right)$ in PS1 cKO;PS2 $2^{+/-}$and PS1 cKO;PS2 $2^{-/-}$mice at 9 months of age, respectively. These results suggest that $\gamma$-secretase activity is further impaired in the cortex of PS1 cKO; $\mathrm{PS}^{+/-}$mice during aging.

We further examined the C-terminal stub of another $\gamma$-secretase substrate, APLP1 (Naruse et al., 1998). Similar to APP, APLP1 CTFs accumulate by $\sim 10$-fold in the cortex of PS1 $\mathrm{CKO} ; P S 2^{+/+}$mice, and the extent of the accumulation is inversely correlated with the dosage of the wild-type PS2 gene (Fig. $7 B)$. For example, at 2 months of age, levels of APLP1 CTFs are increased at $\sim 1.2$-fold $(p=0.156)$ and $\sim 1.6$-fold $(p=2.700 \times$ $\left.10^{-3}\right)$ in $P S 1 \mathrm{cKO} ; P S 2^{+/-}$and $P S 1 \mathrm{cKO} ; P S 2^{-1-}$ mice, respectively (Fig. $7 B$ ). Furthermore, at 9 months of age, levels of APLP1 CTFs are increased by $\sim 1.4$-fold $\left(p=2.493 \times 10^{-3}\right)$ and $\sim 1.8$ fold $\left(p=8.411 \times 10^{-4}\right)$ in the cerebral cortex of PS1 cKO; $P S 2^{+/-}$and PS1 cKO;PS2 ${ }^{-/-}$mice, respectively. These results demonstrated that $\gamma$-secretase activities are modulated by the presence of both PS1 and PS2 proteins and that, in the absence of PS1, $\gamma$-secretase activity is dependent on the dosage of the PS2 gene.

\section{Discussion}

Complete inactivation of presenilin or nicastrin in excitatory neurons of the adult cerebral cortex results in striking agedependent, progressive neurodegeneration, as well as synaptic and memory impairment (Beglopoulos et al., 2004; Saura et al., 2004; Tabuchi et al., 2009; Zhang et al., 2009, 2010; WinesSamuelson et al., 2010; Wu et al., 2013; Lee et al., 2014). These findings demonstrate the essential role of presenilin $/ \gamma$-secretase in neuronal survival, synaptic function, and memory in the adult brain. The fact that complete loss of presenilin or $\gamma$-secretase recapitulates key features of $\mathrm{AD}$, including age-dependent loss of synapses and neurons, increases of apoptotic neuronal death, inflammatory responses, tau hyperphosphorylation, and progressive impairment of memory and other behavior, suggested that loss of essential PS function by PSEN mutations may under- 
A

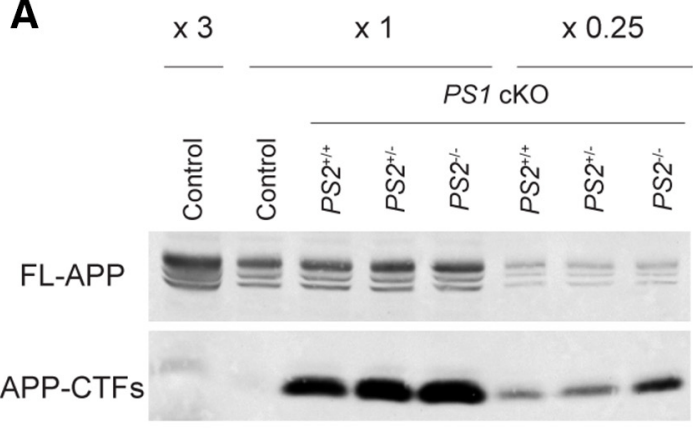

B

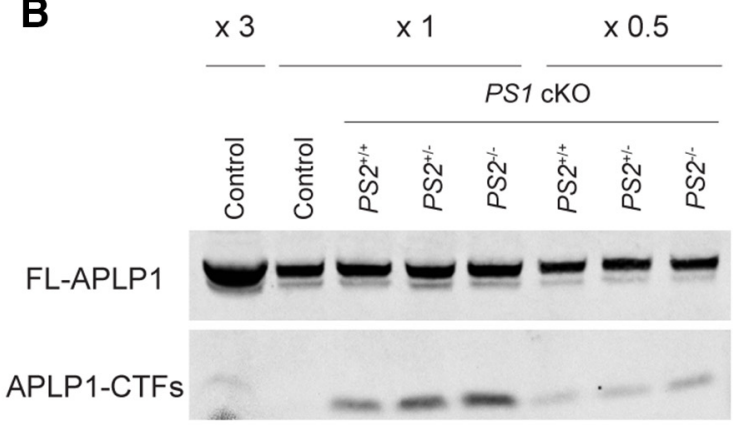

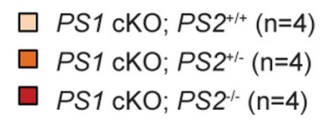
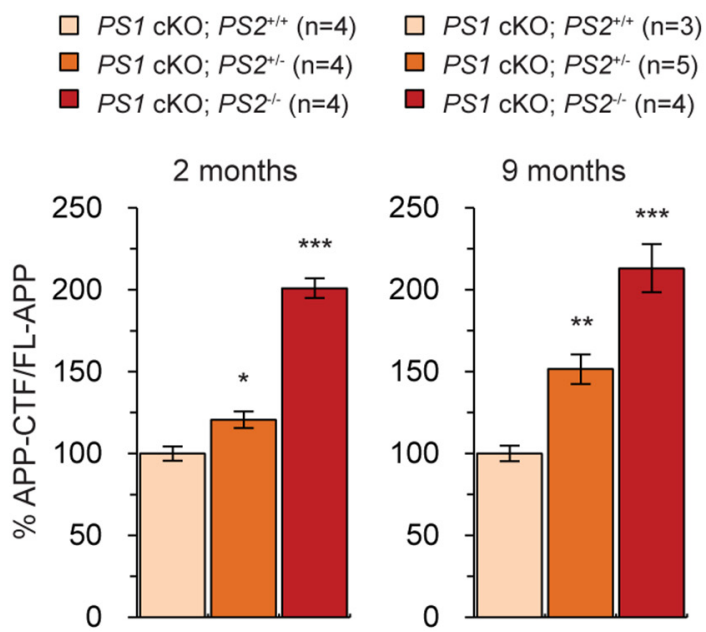

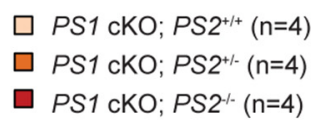

$\square P S 1 \mathrm{cKO} ; P S 2^{+/+}(\mathrm{n}=3)$

$\square P S 1 \mathrm{cKO} ; P^{-/-}(\mathrm{n}=4)$

$\square P S 1 \mathrm{cKO} ; P S 2^{+/-}(\mathrm{n}=5)$

$\square P S 1 \mathrm{cKO} ; \mathrm{SS}^{-/ .}(\mathrm{n}=4)$

2 months

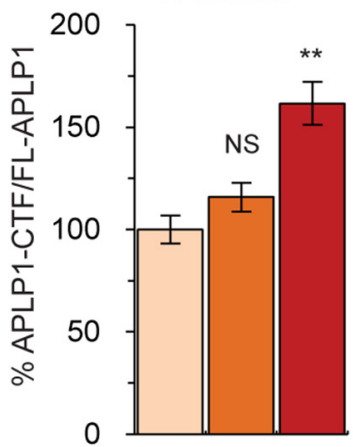

9 months

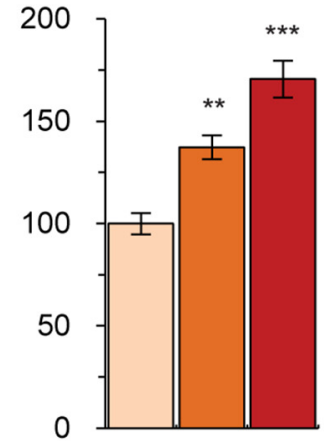

Figure 7. Accumulation of the CTFs of APP and APLP1 in the cerebral cortex of PS1 $\mathrm{CKO}_{2} P S 2^{+/+}, P S 1 \mathrm{CKO} ; P S 2^{+/-}$, and PS1 $\mathrm{CKO}^{+P S 2^{-/-}}$mice. $A, B$, Unchanged levels of full-length APP and increased levels of the CTFs of APP $(\boldsymbol{A})$ and APLP1 $(\boldsymbol{B})$ in the cerebral cortex of PS1 CK0;PS2 ${ }^{+/+}$, PS1 CK0;PS2 ${ }^{+/-}$, and PS1 CKO;PS2 ${ }^{-/-}$mice at 2 and 9 months of age. Immunoblotting (top) was performed using antibodies specific for the APP C terminus $(\boldsymbol{A})$ or the APLP1 C terminus $(\boldsymbol{B})$. Varying amounts of cortical lysates were loaded in each lane. Lanes 1 and 2 were loaded with $3 \times$ and $1 \times$ amounts of cortical lysates from control mice, and the rest of the lanes were loaded with $1 \times($ lanes $3-5), 0.25 \times(A$, lanes $6-8)$, or $0.5 \times(B$, lanes $6-8)$ of cortical lysates from $P S 1$ CKO;PS2 $2^{+/+}, P S 1 \mathrm{CKO} ; P S 2^{+/-}$, and PS1 CKO;PS2 $2^{-\prime-}$ mice. Levels of the CTFs were quantified and normalized to the full-length proteins (bottom). Quantification analysis shows a massive increase of the CTFs in the cerebral cortex of PS1 CKO;PS2 ${ }^{+/+}$mice and additional increases in PS1 CK0;PS2 ${ }^{+/}$and PS1 CKO;PS2 $2^{-/-}$mice. The value of the CTFs in PS1 CKO;PS2 ${ }^{+/+}$mice is set as $100 \%$. NS, Not significant. ${ }^{*} p<0.05 ;{ }^{* *} p<0.01{ }^{* * *} p<0.001$.

lie neurodegeneration and dementia in $\mathrm{AD}$ (Shen and Kelleher, 2007). This view is further supported by findings in Caenorhabditis elegans, Drosophila, and mammalian cultured cells showing that PSEN mutations result in partial to complete loss of its function or $\gamma$-secretase activity (Levitan et al., 1996; Song et al., 1999; Seidner et al., 2006; Heilig et al., 2010). However, whether partial loss of PS indeed results in neurodegeneration has not been tested experimentally. The current study was designed to address this question through the generation of $P S 1 \mathrm{cKO}$ mice carrying varying doses of the PS2 gene. We found that $P S 1 \mathrm{cKO} ; P S 2^{+/-}$mice exhibit significant neurodegeneration in the cerebral cortex, with $\sim 17 \%$ loss of cortical volume and neuron number at 16 months of age compared with the more severe neurodegeneration in PS1 cKO;PS2 $2^{-1-}$ mice, with $\sim 50 \%$ reduction of cortical volume and neuron number (Fig. 1). Neurodegeneration in PS1 cKO;PS2 ${ }^{+/-}$ mice is also accompanied by increases of apoptosis (Fig. 3), as well as astrogliosis (Fig. 4) and microgliosis (Fig. 5). At 4 months of age, significant loss of cortical volume and neuron number was observed in PS1 cKO;PS2 ${ }^{-/-}$mice but not in $P S 1 \mathrm{cKO} ; \mathrm{PS}^{+/-}$ mice (Fig. 2). Consistent with these findings, increased apoptosis was seen in PS1 $\mathrm{cKO} ; \mathrm{PS}^{+/-}$mice at 16 months but not at 4 months compared with dramatic increases of apoptosis in PS1 cKO;PS2 ${ }^{-1-}$ mice at 4 months, suggesting a later onset of apoptosis in PS1 cKO;PS2 ${ }^{+/-}$mice (Fig. 3). Thus, loss of PS activity indeed leads to neurodegeneration and increases of apoptotic cell death in an age- and PS dose-dependent manner.

PS1 and PS2 share $\sim 67 \%$ sequence homology and are functional homologs (Levy-Lahad et al., 1995; Rogaev et al., 1995). PS1 appears to be more important than PS2 in performing presenilin functions, because PS1 germ-line KO mice die at birth and PS2 KO mice have little detectable phenotypes. However, in the absence of PS1, PS2 does play essential roles. For example, mice lacking both PS1 and PS2 die much earlier than PS1 KO mice at embryonic day 9 (Shen et al., 1997; Donoviel et al., 1999), and the neurogenesis defects caused by loss of both presenilins in neural progenitor cells are much more severe than those observed in neural progenitor cell-restricted PS1 cKO mice (Shen et al., 1997; Handler et al., 2000; Wines-Samuelson et al., 2005; Kim and Shen, 2008). Similarly, in the adult brain, PS cDKO mice lacking both presenilins in excitatory neurons of the adult cerebral cortex develop striking neurodegeneration and severe memory impairment during aging, whereas PS1 cKO mice exhibit mild memory impairment but no neurodegeneration (Yu et al., 2001; Saura et al., 2004; Wines-Samuelson et al., 2010; Fig. 1). Consistent with these in vivo findings, in vitro $\gamma$-secretase assay showed that membrane fractions from $P S 1^{+/-} ; P S 2^{-/-}$and $P S 1^{-/-} ; P S 2^{+/+}$cells have 56 and $11 \%$ of $\gamma$-secretase activity, respectively, compared with those derived from $P S 1^{+/+} ; P S 2^{+/+}$cells, suggesting that 
PS1 is $\sim 10$-fold more active than PS2 (Lai et al., 2003). Furthermore, ablation of the PS2 gene alone in mice did not affect both accumulation of APP CTFs and $\beta$-amyloid $(\mathrm{A} \beta)$ production (Steiner et al., 1999), whereas conditional inactivation of PS1 selectively in excitatory neurons of the adult cerebral cortex leads to 30 -fold accumulation of APP CTFs and reduction of A $\beta$ production at 6 months of age (Yu et al., 2001). In this study, we showed that accumulation of the CTFs of APP and APLP1 in the mouse brain correlates with PS dosage and that loss of one or two copies of the PS2 gene in PS1 cKO mice results in increasingly greater accumulation of the CTFs (Fig. 7). The accumulation of APP CTFs in the cerebral cortex of PS1 cKO;PS2 ${ }^{-1-}$ mice is approximately twice as much as that in $P S 1 \mathrm{cKO}$ mice, which accumulate APP CTFs $>10$-fold compared with control mice (Fig. 7). Thus, both in vivo and in vitro analysis showed that PS $1 / \gamma$ secretase is much more potent than PS $2 / \gamma$-secretase, although a recent study using a yeast reconstitution system showed that the amount of active PS1 containing $\gamma$-secretase complex is much greater than PS2 containing $\gamma$-secretase and that the activity of PS1 or PS2 in single $\gamma$-secretase complex is similar (Yonemura et al., 2011).

The failure to detect significant neuronal degeneration in PS1 cKO mice at 16 months of age is somewhat surprising, because most, if not all, cortical pyramidal neurons lack PS1 in the cerebral cortex of $P S 1 \mathrm{cKO}$ mice beginning at $\sim 1$ month of age (Yu et al., 2001). Interestingly, PS2 is upregulated in these mice, as indicated by $\sim 30 \%$ increase of PS2 CTFs in the cerebral cortex of $P S 1 \mathrm{cKO} ; P S 2^{+/+}$mice at 2 months of age (Fig. 6). Given the fact that the PS1 cKO cerebral cortex is mosaic with PS1 inactivated only in excitatory neurons but not in interneurons or glia, the increase of PS2 in individual excitatory neurons is likely to be greater than the $30 \%$ increase detected by Western blotting using cortical lysates. Thus, the upregulation of PS2 may provide additional protection against neurodegeneration in PS1 cKO mice at this age (Fig. 1). The upregulation of PS2 protein in PS1-deficient cells might be attributable to enhanced formation of the PS $2 / \gamma$ secretase complex, which stabilizes PS2 protein, because of increased availability of other subunits, such as nicastrin, Aph-1, and Pen- 2 in the absence of PS1. Similarly, more PS2 was detected in cortical lysates of PS1 cKO;PS2 ${ }^{+/-}$mice (Fig. 6), suggesting that neurodegeneration detected in these mice may be otherwise more severe (Fig. 1). Furthermore, a recent report indicated that PS2 containing $\gamma$-secretase in microglia plays a role in protection from neuronal cell death by suppressing neuroinflammatory responses (Jayadev et al., 2010). Although this may explain the severe neurodegeneration and gliosis observed in $P S$ cDKO mice, in which PS2 is eliminated, it cannot explain similarly severe neurodegeneration and gliosis observed in Nct cKO mice, in which PS2 expression is intact in microglia (Tabuchi et al., 2009). Although one copy of PS2 is insufficient to prevent agedependent neurodegeneration, one copy of PS1 in germ-line $P S 1^{+/-} ; P S 2^{-/-}$mice (Tournoy et al., 2004) or conditional $P S 1^{\text {floxed } /+} ; P S 2^{-/-} ;$Cre mice (D. Xia and J.S., unpublished data) is sufficient to prevent neurodegeneration in the brain, although defects in the peripheral systems were reported, including benign skin hyperplasia, splenomegaly, and leukocytosis (Qyang et al., 2004; Tournoy et al., 2004). These results are consistent with more prominent role of PS1 in maintaining $\gamma$-secretase activity and brain functions.

In summary, we demonstrate that, during aging, survival of excitatory neurons in the cerebral cortex is dependent on the dosage of the presenilin genes. These excitatory neurons are particularly vulnerable in $\mathrm{AD}$ and normally express high levels of the
PS genes. Partial to complete loss of presenilins results in progressively more severe neuronal degeneration and earlier onset of increased apopototic cell death. The milder neurodegeneration and the later onset of apoptosis in PS1 cKO;PS2 $2^{+/-}$mice are more reminiscent of the progressive neurodegeneration in $\mathrm{AD}$, in contrast to the striking and earlier onset of neurodegeneration in $P S \mathrm{cDKO}$ mice. This is the first experimental evidence showing that partial loss of presenilins is sufficient to cause neuronal cell death in the mouse brain during aging. Considering the fact that FAD mutations in the PSEN genes are loss-of-function mutations (Levitan et al., 1996; Song et al., 1999; Moehlmann et al., 2002; Seidner et al., 2006; Shen and Kelleher, 2007; Heilig et al., 2010) and that expression and activity of presenilins $/ \gamma$-secretase is attenuated in aged mouse brains (Placanica et al., 2009), the current study provides additional experimental support for the loss of PS function underlying neurodegeneration in FAD and AD.

\section{References}

Beglopoulos V, Sun X, Saura CA, Lemere CA, Kim RD, Shen J (2004) Reduced beta-amyloid production and increased inflammatory responses in presenilin conditional knock-out mice. J Biol Chem 279:46907-46914. CrossRef Medline

Dewachter I, Reversé D, Caluwaerts N, Ris L, Kuipéri C, Van den Haute C, Spittaels K, Umans L, Serneels L, Thiry E, Moechars D, Mercken M, Godaux E, Van Leuven F (2002) Neuronal deficiency of presenilin 1 inhibits amyloid plaque formation and corrects hippocampal long-term potentiation but not a cognitive defect of amyloid precursor protein [V717I] transgenic mice. J Neurosci 22:3445-3453. Medline

Donoviel DB, Hadjantonakis AK, Ikeda M, Zheng H, Hyslop PS, Bernstein A (1999) Mice lacking both presenilin genes exhibit early embryonic patterning defects. Genes Dev 13:2801-2810. CrossRef Medline

Earnshaw WC, Martins LM, Kaufmann SH (1999) Mammalian caspases: structure, activation, substrates, and functions during apoptosis. Annu Rev Biochem 68:383-424. CrossRef Medline

Feng R, Wang H, Wang J, Shrom D, Zeng X, Tsien JZ (2004) Forebrain degeneration and ventricle enlargement caused by double knockout of Alzheimer's presenilin-1 and presenilin-2. Proc Natl Acad Sci U S A 101: 8162-8167. CrossRef Medline

Handler M, Yang X, Shen J (2000) Presenilin-1 regulates neuronal differentiation during neurogenesis. Development 127:2593-2606. Medline

Heilig EA, Xia W, Shen J, Kelleher RJ 3rd (2010) A presenilin-1 mutation identified in familial Alzheimer disease with cotton wool plaques causes a nearly complete loss of gamma-secretase activity. J Biol Chem 285:22350 22359. CrossRef Medline

Heneka MT, Rodríguez JJ, Verkhratsky A (2010) Neuroglia in neurodegeneration. Brain Res Rev 63:189-211. CrossRef Medline

Ho A, Shen J (2011) Presenilins in synaptic function and disease. Trends Mol Med 17:617-624. CrossRef Medline

Jayadev S, Case A, Eastman AJ, Nguyen H, Pollak J, Wiley JC, Moller T, Morrison RS, Garden GA (2010) Presenilin 2 is the predominant gamma-secretase in microglia and modulates cytokine release. PLoS One 5:e15743. CrossRef Medline

Kim WY, Shen J (2008) Presenilins are required for maintenance of neural stem cells in the developing brain. Mol Neurodegener 3:2. CrossRef Medline

Lai MT, Chen E, Crouthamel MC, DiMuzio-Mower J, Xu M, Huang Q, Price E, Register RB, Shi XP, Donoviel DB, Bernstein A, Hazuda D, Gardell SJ, Li YM (2003) Presenilin-1 and presenilin-2 exhibit distinct yet overlapping gamma-secretase activities. J Biol Chem 278:22475-22481. CrossRef Medline

Lee SH, Sharma M, Südhof TC, Shen J (2014) Synaptic function of nicastrin in hippocampal neurons. Proc Natl Acad Sci U S A 111:8973-8978. CrossRef Medline

Levitan D, Doyle TG, Brousseau D, Lee MK, Thinakaran G, Slunt HH, Sisodia SS, Greenwald I (1996) Assessment of normal and mutant human presenilin function in Caenorhabditis elegans. Proc Natl Acad Sci U S A 93: 14940-14944. CrossRef Medline

Levy-Lahad E, Wasco W, Poorkaj P, Romano DM, Oshima J, Pettingell WH, Yu CE, Jondro PD, Schmidt SD, Wang K, Crowley AC, Fu YH, Guenette SY, Galas D, Nemens E, Wijsman EM, Bird TD, Schellenberg GD, Tanzi 
RE (1995) Candidate gene for the chromosome 1 familial Alzheimer's disease locus. Science 269:973-977. CrossRef Medline

Li YM, Xu M, Lai MT, Huang Q, Castro JL, DiMuzio-Mower J, Harrison T, Lellis C, Nadin A, Neduvelil JG, Register RB, Sardana MK, Shearman MS, Smith AL, Shi XP, Yin KC, Shafer JA, Gardell SJ (2000) Photoactivated gamma-secretase inhibitors directed to the active site covalently label presenilin 1. Nature 405:689-694. CrossRef Medline

Lobsiger CS, Cleveland DW (2007) Glial cells as intrinsic components of non-cell-autonomous neurodegenerative disease. Nat Neurosci 10:13551360. CrossRef Medline

Moehlmann T, Winkler E, Xia X, Edbauer D, Murrell J, Capell A, Kaether C, Zheng H, Ghetti B, Haass C, Steiner H (2002) Presenilin-1 mutations of leucine 166 equally affect the generation of the Notch and APP intracellular domains independent of their effect on Abeta 42 production. Proc Natl Acad Sci U S A 99:8025-8030. CrossRef Medline

Naruse S, Thinakaran G, Luo JJ, Kusiak JW, Tomita T, Iwatsubo T, Qian X, Ginty DD, Price DL, Borchelt DR, Wong PC, Sisodia SS (1998) Effects of PS1 deficiency on membrane protein trafficking in neurons. Neuron 21: 1213-1221. CrossRef Medline

Placanica L, Zhu L, Li YM (2009) Gender- and age-dependent gammasecretase activity in mouse brain and its implication in sporadic Alzheimer disease. PLoS One 4:e5088. CrossRef Medline

Qyang Y, Chambers SM, Wang P, Xia X, Chen X, Goodell MA, Zheng H (2004) Myeloproliferative disease in mice with reduced presenilin gene dosage: effect of gamma-secretase blockage. Biochemistry 43:5352-5359. CrossRef Medline

Rogaev EI, Sherrington R, Rogaeva EA, Levesque G, Ikeda M, Liang Y, Chi H, Lin C, Holman K, Tsuda T, Mar L, Sorbi S, Nacmias B, Piacentini S, Amaducci L, Chumakov I, Cohen D, Lannfelt L, Fraser PE, Rommens JM, St George-Hyslop PH (1995) Familial Alzheimer's disease in kindreds with missense mutations in a gene on chromosome 1 related to the Alzheimer's disease type 3 gene. Nature 376:775-778. CrossRef Medline

Saura CA, Choi SY, Beglopoulos V, Malkani S, Zhang D, Shankaranarayana Rao BS, Chattarji S, Kelleher RJ 3rd, Kandel ER, Duff K, Kirkwood A, Shen J (2004) Loss of presenilin function causes impairments of memory and synaptic plasticity followed by age-dependent neurodegeneration. Neuron 42:23-36. CrossRef Medline

Saura CA, Chen G, Malkani S, Choi SY, Takahashi RH, Zhang D, Gouras GK, Kirkwood A, Morris RG, Shen J (2005) Conditional inactivation of presenilin 1 prevents amyloid accumulation and temporarily rescues contextual and spatial working memory impairments in amyloid precursor protein transgenic mice. J Neurosci 25:6755-6764. CrossRef Medline

Seidner GA, Ye Y, Faraday MM, Alvord WG, Fortini ME (2006) Modeling clinically heterogeneous presenilin mutations with transgenic Drosophila. Curr Biol 16:1026-1033. CrossRef Medline

Shen J, Bronson RT, Chen DF, Xia W, Selkoe DJ, Tonegawa S (1997) Skeletal and CNS defects in Presenilin-1-deficient mice. Cell 89:629-639. CrossRef Medline
Shen J, Kelleher RJ 3rd (2007) The presenilin hypothesis of Alzheimer's disease: evidence for a loss-of-function pathogenic mechanism. Proc Natl Acad Sci U S A 104:403-409. CrossRef Medline

Song W, Nadeau P, Yuan M, Yang X, Shen J, Yankner BA (1999) Proteolytic release and nuclear translocation of Notch-1 are induced by presenilin-1 and impaired by pathogenic presenilin-1 mutations. Proc Natl Acad Sci U S A 96:6959-6963. CrossRef Medline

Steiner H, Duff K, Capell A, Romig H, Grim MG, Lincoln S, Hardy J, Yu X, Picciano M, Fechteler K, Citron M, Kopan R, Pesold B, Keck S, Baader M, Tomita T, Iwatsubo T, Baumeister R, Haass C (1999) A loss of function mutation of presenilin-2 interferes with amyloid beta-peptide production and notch signaling. J Biol Chem 274:28669-28673. CrossRef Medline

Tabuchi K, Chen G, Südhof TC, Shen J (2009) Conditional forebrain inactivation of nicastrin causes progressive memory impairment and agerelated neurodegeneration. J Neurosci 29:7290-7301. CrossRef Medline

Tournoy J, Bossuyt X, Snellinx A, Regent M, Garmyn M, Serneels L, Saftig P, Craessaerts K, De Strooper B, Hartmann D (2004) Partial loss of presenilins causes seborrheic keratosis and autoimmune disease in mice. Hum Mol Genet 13:1321-1331. CrossRef Medline

Wines-Samuelson M, Shen J (2005) Presenilins in the developing, adult, and aging cerebral cortex. Neuroscientist 11:441-451. CrossRef Medline

Wines-Samuelson M, Handler M, Shen J (2005) Role of presenilin-1 in cortical lamination and survival of Cajal-Retzius neurons. Dev Biol 277:332346. CrossRef Medline

Wines-Samuelson M, Schulte EC, Smith MJ, Aoki C, Liu X, Kelleher RJ 3rd, Shen J (2010) Characterization of age-dependent and progressive cortical neuronal degeneration in presenilin conditional mutant mice. PLoS One 5:e10195. CrossRef Medline

Wu B, Yamaguchi H, Lai FA, Shen J (2013) Presenilins regulate calcium homeostasis and presynaptic function via ryanodine receptors in hippocampal neurons. Proc Natl Acad Sci U S A 110:15091-15096. CrossRef Medline

Yamaguchi H, Shen J (2013) Histological analysis of neurodegeneration in the mouse brain. Methods Mol Biol 1004:91-113. CrossRef Medline

Yonemura Y, Futai E, Yagishita S, Suo S, Tomita T, Iwatsubo T, Ishiura S (2011) Comparison of presenilin 1 and presenilin 2 gamma-secretase activities using a yeast reconstitution system. J Biol Chem 286:4456944575. CrossRef Medline

Yu H, Saura CA, Choi SY, Sun LD, Yang X, Handler M, Kawarabayashi T, Younkin L, Fedeles B, Wilson MA, Younkin S, Kandel ER, Kirkwood A, Shen J (2001) APP processing and synaptic plasticity in presenilin-1 conditional knockout mice. Neuron 31:713-726. CrossRef Medline

Zhang C, Wu B, Beglopoulos V, Wines-Samuelson M, Zhang D, Dragatsis I, Südhof TC, Shen J (2009) Presenilins are essential for regulating neurotransmitter release. Nature 460:632-636. CrossRef Medline

Zhang D, Zhang C, Ho A, Kirkwood A, Südhof TC, Shen J (2010) Inactivation of presenilins causes pre-synaptic impairment prior to post-synaptic dysfunction. J Neurochem 115:1215-1221. CrossRef Medline 